\title{
Gas Production Potential of DisPerse Low-SATURATION HYDRATE ACCUMULATIONS IN OCEANIC SEDIMENTS
}

\section{George J. Moridis}

Earth Sciences Division

Lawrence Berkeley National Laboratory

Berkeley, CA 94720

\section{E. Dendy Sloan}

Center for Hydrate Research and

Chemical Engineering Department

Colorado School of Mines

Golden, CO 80401

\section{August 2006}




\title{
Gas Production Potential of Disperse Low-Saturation Hydrate Accumulations in Oceanic Sediments
}

\author{
George J. Moridis ${ }^{1}$ and E. Dendy Sloan ${ }^{2}$ \\ ${ }^{1}$ Earth Sciences Division, Lawrence Berkeley National Laboratory, MS 90-1166 \\ University of California, Berkeley, California 94720, USA \\ E-mail: GJMoridis@lbl.gov \\ 2 Chemical Engineering Department \\ Colorado School of Mines, Golden, Colorado 80401, USA \\ E-mail:Esloan@mines.edu
}

\begin{abstract}
In this paper we evaluate the gas production potential of disperse, low-saturation $\left(S_{H}<\right.$ 0.1) hydrate accumulations in oceanic sediments. Such hydrate-bearing sediments constitute a significant portion of the global hydrate inventory. Using numerical simulation, we estimate (a) the rates of gas production and gas release from hydrate dissociation, (b) the corresponding cumulative volumes of released and produced gas, as well as (c) the water production rate and the mass of produced water from disperse, low$S_{H}$ hydrate-bearing sediments subject to depressurization-induced dissociation over a 10 year production period. We investigate the sensitivity of items (a) to (c) to the following hydraulic properties, reservoir conditions, and operational parameters: intrinsic permeability, porosity, pressure, temperature, hydrate saturation, and constant pressure at which the production well is kept. The results of this study indicate that, despite wide variations in the aforementioned parameters (covering the entire spectrum of such deposits), gas production is very limited, never exceeding a few thousand cubic meters of
\end{abstract}


gas during the 10-year production period. Such low production volumes are orders of magnitude below commonly accepted standards of economic viability, and are further burdened with very unfavorable gas-to-water ratios. The unequivocal conclusion from this study is that disperse, low- $S_{H}$ hydrate accumulations in oceanic sediments are not promising targets for gas production by means of depressurization-induced dissociation, and resources for early hydrate exploitation should be focused elsewhere.

\section{Keywords}

Methane hydrates, hydrate-bearing sediments, disperse hydrates, low-saturation, oceanic systems, depressurization, gas production

\section{Nomenclature}

$$
\begin{aligned}
\Delta r & =\text { Radial increment }(\mathrm{sec}) \\
\Delta z & =\text { Vertical discretization in the z-direction }(\mathrm{m}) \\
k & =\text { intrinsic permeability }\left(\mathrm{m}^{2}\right) \\
k_{\Theta} & =\text { composite thermal conductivity }(\mathrm{W} / \mathrm{m} / \mathrm{K}) \\
k_{S d} & =\text { "dry" thermal conductivity }(\mathrm{W} / \mathrm{m} / \mathrm{K}) \\
k_{S w} & =\text { "wet" thermal conductivity }(\mathrm{W} / \mathrm{m} / \mathrm{K}) \\
M_{W} & =\text { cumulative mass of water produced at the well }(\mathrm{kg}) \\
N_{H} & =\text { hydration number } \\
P & =\text { pressure }(\mathrm{Pa}) \\
Q_{R} & =\text { volumetric rate of } \mathrm{CH}_{4} \text { release from dissociation }\left(\mathrm{ST} \mathrm{m}^{3} / \mathrm{s}\right) \\
Q_{P} & =\text { volumetric rate of } \mathrm{CH}_{4} \text { release from dissociation }(\mathrm{ST} \mathrm{m} / \mathrm{s})
\end{aligned}
$$




$$
\begin{aligned}
Q_{W} & =\text { mass rate of water production at the well }(\mathrm{kg} / \mathrm{s}) \\
r, z & =\text { coordinates }(\mathrm{m}) \\
R_{\max } & =\text { reservoir radius }(\mathrm{m}) \\
R_{w} & =\text { well radius }(\mathrm{m}) \\
V_{R} & =\text { cumulative volume of } \mathrm{CH}_{4} \text { released from dissociation }\left(\mathrm{ST} \mathrm{m}^{3}\right) \\
V_{P} & =\text { cumulative volume of } \mathrm{CH}_{4} \text { produced at the well }\left(\mathrm{ST} \mathrm{m}^{3}\right) \\
S & =\text { phase saturation } \\
t & =\text { time }(\mathrm{s}) \\
T & =\text { temperature }\left({ }^{0} \mathrm{C}\right)
\end{aligned}
$$

\section{Greek Symbols}

$$
\begin{aligned}
& \lambda=\text { van Genuchten exponent } \\
& \phi=\text { porosity }
\end{aligned}
$$

\section{Subscripts and Superscripts}

$$
\begin{aligned}
0 & =\text { denotes initial state } \\
A & =\text { aqueous phase } \\
G & =\text { gas phase } \\
H & =\text { solid hydrate phase } \\
n & =\text { permeability reduction exponent } \\
\operatorname{ir} G & =\text { irreducible gas } \\
\operatorname{ir} A & =\text { irreducible aqueous phase }
\end{aligned}
$$




\section{Introduction}

\subsection{Background}

Gas hydrates are solid crystalline compounds in which small gas molecules (referred to as guests) are lodged within the lattices of ice crystals (called hosts). Under suitable conditions of low temperature and high pressure, a gas $\mathrm{G}$ will react with water to form hydrates according to:

$$
\mathrm{G}+N_{H} \mathrm{H}_{2} \mathrm{O}=\mathrm{G} \bullet N_{H} \mathrm{H}_{2} \mathrm{O},
$$

where $N_{H}$ is the hydration number. Of particular interest are hydrates formed by hydrocarbon gases when $\mathrm{G}$ is an alkane, especially methane, $\mathrm{CH}_{4}$. Natural hydrates in geological systems also include $\mathrm{CO}_{2}, \mathrm{H}_{2} \mathrm{~S}$ and $\mathrm{N}_{2}$ as guests. Of particular interest are hydrates formed by methane $\left(\mathrm{G}=\mathrm{CH}_{4}\right)$, in which case $N_{H}=6$, and one volume of hydrates contains about 164 volumes (STP) of gas. Natural hydrate deposits involve mainly $\mathrm{CH}_{4}$, and occur in two distinctly different geologic settings where the necessary low temperatures and high pressures exist for their formation and stability: in the permafrost and in deep ocean sediments.

Hydrates find application in energy for flow assurance [1] and in resource assessment [2], as well as in climate change [3] and seafloor stability [4,5] and gas transportation and storage [6]. While the first of these applications has been the principal driving force for hydrate research for almost seven decades, the latter applications have recently become the subject of intensive research. This work assesses only the resource aspect of hydrates, and is further limited to disperse, low-saturation accumulations in marine geologic media. Such accumulations are a common (and possibly the prevalent) type of 
oceanic hydrate deposits, are referred to as Class 4 hydrate deposits, and differ significantly in their behavior and gas production potential from Classes 1 to 3 [7,8], i.e., the types of hydrate deposits currently considered as the most promising targets for light hydrocarbon recovery.

\subsection{Natural Hydrate Accumulations as a Hydrocarbon Resource}

In his most recent compilation of hydrates in nature, Kvenvolden [9] lists 89 world-wide occurrences of hydrates, with hydrate evidence from acoustic waves (63 instances), sample recovery (23 instances), and other inferences (6 instances). Further review reveals two striking facts: (1) $99 \%$ of all natural hydrates are composed of biogenic methane, and (2) the amount of methane in ocean hydrates is approximately two orders of magnitude greater than the amount of methane in permafrost hydrates.

Although estimates of the amount of methane in hydrates have decreased significantly over the last three decades, the two most recent estimates differ substantially: $2.5 \times 10^{15} \mathrm{~m}^{3}$ [10] and $120 \times 10^{15} \mathrm{~m}^{3}$ STP [11]. Given the escalating global energy demand and the correspondingly rising hydrocarbon cost, the economic appeal of hydrate deposits as an emerging potential gas source is rapidly increasing (despite such disparate estimates, and even if only a fraction of the trapped gas were recoverable) when compared to the conventional gas reserve of $0.15 \times 10^{15} \mathrm{~m}^{3}$ methane (STP) [12]. The attractiveness of hydrates is further augmented by the environmental desirability of gas (as opposed to solid and liquid) fuels. 
Many of the methane recovery schemes from hydrates involve one (or combinations) of three methods indicated by the hydrate pioneer Y. Makogon [13,14]: (1) depressurization, (2) thermal stimulation, and (3) inhibitor injection. Although other techniques have been proposed, they have yet to emerge as plausible alternatives to the aforementioned three main dissociation methods. Note that every method must obey the principles of (a) thermodynamics, (b) mass balances, (c) energy balances, and (d) momentum balances. In terms of physics and mathematics, the current work involves the application and maintenance of these four balances to the problem of gas production from the common Class 4 ocean hydrate occurrence.

\subsection{Objectives and Approach in this Study}

The broader aim of this work is to identify the most promising Hydrate-Bearing Sediments (HBS) for early concentration of effort and resources (including scientific analysis, engineering research, exploration, and field testing). The accumulations investigated here constitute a large part of the oceanic hydrate inventory. The focus of this specific study is to evaluate the production potential of Class $4 \mathrm{HBS}$, and determine whether resources should be devoted to investigate these as a gas resource at this early stage of the hydrate exploitation endeavor.

Since field data are the most reliable guide to reality, consider first the inventory of known hydrate samples from Booth et al. [15] in Figure 1. The curved line separates the hydrate stability region to the left, from the right, which gives the conditions of gas coexisting with water. The samples occur roughly in three groups: (1) a small set of 
samples at $2{ }^{\circ} \mathrm{C}$, such as those at Eel River, Okhotsk-Paramushir, and Okhotk-Sahkalin, (2) a larger set of samples at $6{ }^{\circ} \mathrm{C}$, such as those at the Cascadia Margin, the Gulf of Mexico, and the Middle America Trench off Mexico, and (3) a smaller sample set at 12 ${ }^{\circ} \mathrm{C}$, consisting of the Blake Ridge, the Middle America Trench off Guatemala, and the Peru-Chile Trench 2.

The sample inventory in Figure 1 provides a perspective about which resources could be recovered by the various techniques. For example for thermal stimulation to be economical, the energy of combustion from hydrated methane must equal or exceed that of the sensible heat to move the hydrated sample to the phase boundary plus the heat of dissociation to convert hydrate to gas and water. If we assume that the hydrate saturation $S_{H}=0.035$ in a sediment with a porosity $\phi=0.30$, the energy balance indicates that only samples less than $19{ }^{\circ} \mathrm{C}$ below the phase equilibrium line will be economical at $100 \%$ efficient recovery [16].

Similar calculations have led hydrate researchers to conclude also that inhibitor injection is the most expensive technique for methane recovery from hydrates, followed by thermal stimulation, with depressurization as the most inexpensive recovery method [17]. Put another way, if depressurization is not economical, then thermal stimulation or inhibitor injection will never have a net positive return.

The main objective in this study was to use a state-of-the-art numerical reservoir simulator (a) to determine the feasibility of recovering via depressurization gas from the 
common type of Class 4 methane hydrates in oceanic sediments, and (b) to identify and quantify the relative importance of the physical conditions and production parameters that affect production.

\section{The numerical simulation study}

\subsection{The numerical model}

The numerical studies in this paper were conducted using the TOUGH-Fx/HYDRATE simulator [18], which can model the non-isothermal hydration reaction, phase behavior and flow of fluids and heat under conditions typical of natural $\mathrm{CH}_{4}$-hydrate deposits in complex geologic media. It includes both an equilibrium and a kinetic model $[19,20]$ of the methane hydrate formation and dissociation. The model accounts for heat and up to four mass components (i.e., water, $\mathrm{CH}_{4}$, hydrate, and water-soluble inhibitors such as salts or alcohols) that are partitioned among four possible phases: gas phase, aqueous phase, ice phase, and hydrate phase. A total of 12 states (phase combinations) can be described by the code, which can handle any combination of the possible hydrate dissociation methods (i.e., depressurization, thermal stimulation, and inhibitor-induced effects). TOUGH-Fx/HYDRATE involves a fully implicit formulation, continuous property updating, and the Newton-Raphson iteration for the solution of the nonlinear coupled equations of fluid and heat flow. The resulting Jacobian matrix equation is capable of handling the phase changes and steep solution surfaces that are typical of hydrate problems [8]. 


\subsection{System Description and Simulation Approach}

\subsubsection{Basic domain description}

The studies in this paper are based on a domain that involves an infinite-acting 1-D radial system of uniform unit thickness of $(\Delta z=1 \mathrm{~m})$. Such a system implicitly assumes no hydraulic and thermal communication with its surroundings (i.e., no fluid and heat exchange with its upper and lower boundary), and is a realistic representation of conditions in a deep HBS under production using a well with a long production interval. The assumption of no hydraulic communication is valid in thin layers (subdomains) within deep uniform HBS when the flow is predominantly horizontal, i.e., when the production interval of the well covers the entire thickness of the HBS (thus corresponding to the best-case scenario, yielding maximum estimates of gas production).

Under the conditions of natural HBS, the assumption of no thermal communication (i.e., no heat exchange with its surroundings) is not strictly true, but the approximation can be considered valid in the thin $\Delta z=1 \mathrm{~m}$ basic domain. The small deviations from validity are caused by the small geothermal gradient within the HBS (generally $d T / d z=0.03$ $\mathrm{K} / \mathrm{m}$ ) and the strong sensitivity of hydrates to temperature, are averaged (and possibly balanced) within the domain thickness, and are overwhelmed by the very strong thermal response of the system in the course of dissociation for gas production. Additionally, the issue is addressed by investigating the sensitivity of production to temperature and pressure variations. Consequently, this study discusses production estimates per unit thickness of a uniform, deep HBS. 
An additional issue is that of system behavior in the vicinity of the HBS boundaries (i.e., where $S_{H}=0$ ) under natural conditions, and how representative our simulated system is. Disperse, low- $S_{H}$ hydrate accumulations are generally expected to:

(i) Occur in deep uniform formations that are hydraulically continuous with the upper bounding hydrate-free formations (i.e., they are not bounded by an impermeable upper boundary or cap rock),

(ii) Lack an impermeable lower bounding formation (the existence of which could prevent gas rise from deeper formation and hydrate formation), and

(iii) Have their deepest occurrence determined by the bottom of the hydrate stability zone (see Figure 1).

This being the case, production from a layer near the upper and lower boundaries of a hydrate accumulation would result in reduced gas production because the zone of depressurization would extend significantly into the hydrate-free (and, thus, nonproducing) formations. In that respect, our approach addresses the best-case production scenario corresponding to the inner portion of an HBS, where dissociation behavior and gas production are unaffected by the adverse effect of permeable boundaries.

\subsubsection{Production method}

Production is based on the depressurization-induced dissociation of the hydrates. The low $S_{H}$ of such deposits and the very large thermal inertia of geologic media (involving low composite thermal conductivity and large heat capacity of HBS) precludes any attempt to use pure thermal stimulation by employing direct heating of the subsurface. Such an approach would result in a very limited dissociation radius (that would increase 
very slowly with time), and a low efficiency that would decrease continuously with time as losses through the top and bottom boundaries increase constantly (as their area expands) and the volume of the heated region, which needs to be maintained at a sufficiently high temperature $T$ to ensure dissociation at the hydrate interface, increases with $r^{2}$. It would be possible to consider thermal dissociation in conjunction with depressurization only if both of the following conditions were met: (a) this study showed that depressurization results in promising gas volumes, and (b) a source of warm water (e.g., a deeper warm brine aquifer) was readily available. Therefore, at this early stage of the study only depressurization was considered because it appeared to be the only viable option for the reasons discussed in Section 1.3.

\subsubsection{Well operation}

The well operation in this study is based on fluid production in response to a constant pressure at the well. This approach was instituted to avoid potential complications arising from imposing an arbitrary uniform flow rate upon HBS of widely different properties, which could lead to cavitation were the production rate to exceed the ability of the formation to conduct fluids. The constant well pressure is $P_{w}=2.7 \mathrm{MPa}$, i.e., slightly above the pressure of the quadruple point of $\mathrm{CH}_{4}$-hydrates, thus precluding the formation of ice (an unnecessary, though not prohibiting, complication). This approach, coupled with the 10-year-long production period, provides a consistent estimate of the long-term production potential for all cases investigated in this study. 


\subsection{Simulation Specifics and Evaluation Criteria}

The most important properties and parameters of the simulated HBS system are listed in Table 1. The system was simulated using a cylindrical grid with uniform properties and initial conditions. The domain consisted of a single layer ( $\Delta z=1 \mathrm{~m}$ thick), thus the study provided estimates of gas production per unit thickness of HBS. The well radius was $R_{w}$ $=0.1 \mathrm{~m}$, and the domain radius $R_{\max }=10,000 \mathrm{~m}$ was subdivided into 552 active radial elements with logarithmically distributed segments $\Delta r$, beginning with an initial $\Delta r_{0}=$ $0.05 \mathrm{~m}$. The $R_{\max }$ was sufficiently large to ensure an infinite-acting outer boundary of constant conditions (i.e., pressure $P$, temperature $T$, and phase saturations), which was represented by an additional final element of $\Delta r_{b}=0.001 \mathrm{~m}$. The fine discretization allowed an accurate description of the evolution of conditions in the HRS during the process of depressurization-induced dissociation of the hydrate. Using the equilibrium hydration reaction option in TOUGH-Fx/HYDRATE, the grid resulted in a Jacobian matrix equation that consisted of 1,656 coupled equations.

The simulation period was 10 years, which was deemed sufficiently long to provide realistic estimates of long-term behavior and trends. Because of constant pressure at the well and declining pressure in the domain as time advances, fluid (free gas and water) production at the well was expected to continuously decline with time.

The results obtained from all the simulations included the following: volumetric rate of hydrate-originating gas released in the accumulation $Q_{R}$, volumetric rate of gas produced at the well $Q_{P}$, cumulative volume of gas released from hydrate dissociation $V_{R}$, 
cumulative volume of produced gas $V_{P}$, mass flow rate of produced water at the well $Q_{W}$, and cumulative mass of produced water $M_{W}$. Note that there is a need to differentiate between gas released from hydrate dissociation and produced gas: the released gas has to exceed the irreducible gas saturation before it can flow to the well, and to establish a continuous bank of mobile gas from the dissociation zone to the well before any gas appears at the well. Consequently, it is expected that $Q_{R}>Q_{P}$ and $V_{R}>V_{P}$.

We employed two criteria to evaluate the technical feasibility and gas production potential of disperse, low- $\mathrm{S}_{\mathrm{H}}$ (Class 4) hydrate accumulations in oceanic sediments: an absolute criterion of sufficiently high gas production, and a relative criterion of an acceptably high gas-to-water ratio. Note that a commonly accepted rule-of-thumb is that onshore gas wells are generally considered economically viable if they produce at a longterm sustainable rate $Q_{P}>0.1 \mathrm{~m}^{3} / \mathrm{s}\left(=3 \times 10^{5} \mathrm{ft}^{3} /\right.$ day $)$ with minimal $Q_{W}$, while the complexities and significantly higher costs of offshore gas wells require that $Q_{P}$ exceeds $3 \mathrm{~m}^{3} / \mathrm{s}$ in addition to a very low $Q_{W}$.

\subsection{The reference case}

The simulation results are compared to a reference case, the specifics of which are listed in Table 1. The intrinsic permeability $k=10^{-15} \mathrm{~m}^{2}(1 \mathrm{mD})$ is within the reported range of oceanic sediments, although considerably lower permeabilities are quite common [4]. The porosity $\phi=0.3$ is typical of that in consolidated sediments, but near the lower end of the spectrum in unconsolidated marine sediments near the mudline. Note that in the four prominent in situ hydrate case studies (Messoyakha [21] and Mallik [22] in consolidated 
permafrost sediments, and Blake Ridge [23] and Hydrate Ridge [24] in unconsolidated oceanic formations), estimates of porosity averaged $0.25,0.3,0.5$ and 0.65 , respectively.

The initial temperature was $T_{0}=6{ }^{\circ} \mathrm{C}$, and was consistent with the clustering of temperatures measured in a large number of hydrate samples in oceanic sediments, e.g., Cascadia, Gulf of Mexico Slope, Nigeria, Eel River, Peru-Chile Trench 1, etc. (see Figure 1 [14], and the discussion in Section 1.1.). The initial pressure $P_{0}=5.7 \mathrm{MPa}$ was slightly higher (by $0.2 \mathrm{MPa}=2$ bars) than the equilibrium hydrate pressure $\left(P_{H}=5.5 \mathrm{MPa}\right)$ corresponding to the initial temperature $T_{0}=6{ }^{\circ} \mathrm{C}$.

The initial hydrate saturation $S_{H 0}=0.035$ was consistent with the most recent in situ estimate of Klauda and Sandler [11], who suggested a worldwide value of $S_{H}=0.034$, in contrast to other averages which range as high as $S_{H}=0.05$. The irreducible saturations $S_{i r A}=0.2$ and $S_{i r G}=0.02$ in the relative permeability and capillary pressure equations are reasonable assumptions. Note that the capillary pressure function and parameters describe a mild capillary pressure regime, resulting in favorable gas production.

\section{SENSITIVITY ANALYSIS}

\section{$3.1 \quad$ Perturbation parameters}

The perturbation parameters in the ensuing sensitivity analysis were the following: $k, \phi$, $P_{0}, T_{0}, S_{H 0}$, and $P_{w}$. In each of the sensitivity analysis cases, all parameters other than perturbation parameter remained as in the reference case. 


\subsection{Sensitivity to intrinsic permeability $k$}

Intrinsic permeability $k$ range: $10^{-12} \mathrm{~m}^{2}(1000 \mathrm{mD})$ to $10^{-17} \mathrm{~m}^{2}(0.01 \mathrm{mD})$. The upper limit of $k$ investigated here probably exceeds the expected maximum levels in marine sediments [4].

\subsubsection{Comparison of rates}

The volumetric release and production rates $\left(Q_{R}\right.$ and $Q_{P}$, respectively) per unit thickness of HBS in Figure 2 indicate that, conforming to expectations, (i) $Q_{R}$ and $Q_{P}$ increase with $k$, (ii) for a given $k$, they both decline with time, and (iii) for a given $k, Q_{P}<Q_{R}$ for the reason discussed in Section 2.3. Of particular interest are the absolute and the relative magnitudes of $Q_{R}$ and $Q_{P}$. The general observation is that both $Q_{R}$ and $Q_{P}$ are too low for such HBS to be attractive production targets.

Thus, even in the case of an uncharacteristically permeable HBS with $\mathrm{k}=10^{-12} \mathrm{~m}^{2}$, the release rate $Q_{R}$ is very low (Figure 2a), ranging from about $6 \times 10^{-2} \mathrm{ST} \mathrm{m}^{3} / \mathrm{s}$ at $t=0.1$ days, to $3 \times 10^{-2} \mathrm{ST} \mathrm{m} / \mathrm{s}$ at $t=10$ days, to $1.5 \times 10^{-2}$ at $t=10$ years. The picture is drastically worse for the reference case (in which $Q_{R}$ ranges between $2 \times 10^{-4} \mathrm{ST} \mathrm{m}^{3} / \mathrm{s}$ at $t=0.1$ days to $3.5 \times 10^{-5} \mathrm{ST} \mathrm{m}^{3} / \mathrm{s}$ at $t=10$ years), and practically hopeless for $\mathrm{k}=10^{-17} \mathrm{~m}^{2}$ (in which $Q_{R}$ ranges between $10^{-5} \mathrm{ST} \mathrm{m}^{3} / \mathrm{s}$ at $t=0.1$ days to $7 \times 10^{-6} \mathrm{ST} \mathrm{m}^{3} / \mathrm{s}$ at $t=10$ years).

The situation is even worse in the evolution of $Q_{P}$ over time (Figure 2b), which is of much greater importance than $Q_{R}$ because it represents the possible gas recovery from the HBS. A consistent observation is that, at best, $Q_{P}<0.08 Q_{R}$, i.e., less than $8 \%$ (and as 
low as only $2 \%$ ) of the gas evolving from the depressurization-induced dissociation of the hydrates in the HBS reaches the well (with the rest either immobilized as irreducible gas saturation, or creating the mobile gas zone that makes gas flow to the well possible). $Q_{P}$ being over an order of magnitude lower than the already low $Q_{R}$, the obvious conclusion is that gas production from Class 4 HBS does not appear promising even for the most permeable formations, and even when assuming uncharacteristically thick hydrate beds.

\subsubsection{Comparison of volumes}

The cumulative volumes of hydrate-released and produced gas ( $V_{R}$ and $V_{P}$, respectively) per unit thickness of HBS in Figure 3 show results that are entirely analogous to the observations made from Figure 2. Thus, (i) $V_{R}$ and $V_{P}$ increase with $k$, (ii) for a given $k$, they both decline with time, and (iii) for a given $k, V_{P}<V_{R}$. Comparison of $V_{R}$ in Figure 3a to $V_{P}$ in Figure $3 \mathrm{~b}$ indicates that $V_{P}<0.08 V_{R}$, i.e., less than $8 \%$ of the total volume of released gas ever reaches is produced. Only about $1000 \mathrm{ST} \mathrm{m}^{3}$ of gas were produced per unit HBS thickness in the reference case after 10 years of continuous production, and $V_{P}$ dropped to less than $20 \mathrm{ST} \mathrm{m}$ of gas for the case of the $k=10^{-17} \mathrm{~m}^{2}$ sediment. These production volumes are extremely low, and economic gas production from such hydrate accumulation is next to impossible. When $k$ increases to $10^{-14} \mathrm{~m}^{2}$ and $10^{-13} \mathrm{~m}^{2}, V_{P}$ at the end of the 10-year production period increases to $6.4 \times 10^{3} \mathrm{ST} \mathrm{m}^{3}$ and $5.1 \times 10^{4} \mathrm{ST} \mathrm{m}^{3}$, respectively, i.e., levels that are still very low, and orders of magnitude below those associated with economic feasibility. Even in the best case of $k=10^{-12} \mathrm{~m}^{2}$, only about $4.3 \times 10^{5} \mathrm{ST} \mathrm{m}^{3}$ are produced per unit HBS thickness after 10 years of production. This is 
level is orders of magnitude lower than that corresponding to the minimum economically viable production from an onshore well, and far lower than that for an offshore well.

\subsubsection{Water production}

The mass rate of water production at the well $Q_{W}$, and the corresponding cumulative mass of produced water $M_{W}$ per unit thickness of HBS in Figure 4 provide further evidence of the unattractiveness of Class 4 marine hydrate accumulations as a potential gas source. As expected, (i) $Q_{W}$ and $M_{W}$ increase with $k$, and (ii) for a given $k, Q_{W}$ declines with time. Considering only the best possible case of $k=10^{-12} \mathrm{~m}^{2}$, (in an exaggerated effort to meet of the absolute criterion discussed earlier, while all other cases of $k$ variation fail), $Q_{W}$ varies between $1.6 \mathrm{~kg} / \mathrm{s}$ at $t=0.1$ days to $0.8 \mathrm{~kg} / \mathrm{sec}$ at $t=10$ years, leading to a very low gas-to-water ratio when compared to the corresponding $Q_{P}$ in Figure 2b. Comparing $M_{W}$ $\left(=2.7 \times 10^{8} \mathrm{~kg}\right.$ at $t=10$ years $)$ to $V_{P}$ in Figure $3 \mathrm{~b}$, we determine a gas-to-water ratio of about $1.6 \times 10^{-3} \mathrm{ST} \mathrm{m}{ }^{3}$ of gas per $\mathrm{kg}$ of water (or a mass ratio of about $1.1 \times 10^{-3} \mathrm{~kg}$ of gas per $\mathrm{kg}$ of water). These ratios are unacceptably low for economically viable gas production. Consequently, all cases in the $k$-sensitivity study fail to meet both the absolute and the relative criterion for gas production feasibility.

An additional observation from Figures 2 to 4 is that the relationship between $\log (k)$ and all of $Q_{R}, Q_{P}, V_{R}, V_{P}, Q_{W}$ and $M_{W}$ is sub-linear, in which case a variation in $k$ by an order of magnitude results in a consistent change of a lesser magnitude (and in the same direction) in all these variables. 


\subsection{Sensitivity to Porosity $\phi$}

We varied the porosity $\phi$ between 0.3 and 0.6 , thus covering the realistic $\phi$ range in marine sediments (which generally have higher porosities than onshore formations [1998]). The initial expectation was that higher porosities (for a given $k$ and $S_{H}$ ) would lead to higher $Q_{R}, Q_{P}, V_{R}, V_{P}, Q_{W}$ and $M_{W}$ because of increased availability of hydrate and water in the pore space.

Review of (a) $Q_{R}$ and $Q_{P}$ (Figure 5), (b) $V_{R}$ and $V_{P}$ (Figure 6), and (c) $Q_{W}$ and $M_{W}$ (Figure 7) per unit thickness of HBS leads to observations and conclusions that are very similar to those drawn from Figures 2 to 4 . As expected, for a given $\phi$, (i) all these variables decline with time, and (ii) $Q_{P}<Q_{R}$ and $V_{P}<V_{R}$. Of particular interest is the very weak dependence of all these variables on $\phi$, which, while conforming to expectations (increasing with an increasing $\phi)$, is perceptible only at early times $(\mathrm{t}<100$ days). The reason for this behavior is attributed to the increased storage capacity of the porous medium, which counters the increased gas production resulting from the increased hydrate availability. The weak dependence on $\phi$ and the low gas production from the reference case indicate that natural variations in porosity had practically no effect on the production potential of disperse, low- $S_{H}$ marine deposits, with neither production feasibility criteria being met.

\subsection{Sensitivity to initial pressure $P_{0}$}

At the $T_{0}=6{ }^{\circ} \mathrm{C}$ reference temperature, we varied the $P_{0}$ range from $5.5 \mathrm{MPa}$ to $50 \mathrm{MPa}$. This range covers the $P_{0}-T_{0}$ spectrum of measurements of hydrates in natural marine 
systems (Cascadia, Gulf of Mexico Slope, Nigeria, Eel River, MAT: Mex 1, MAT: Mex 2, MAT: Mex 3, Peru-Chile Trench 1 - see Figure 1 and discussion in Section 1.3). The expectation was that, for a given $T_{0}$, a higher $P_{0}$ would lead to (a) lower $Q_{R}, Q_{P}, V_{R}$ and $V_{P}$ because of the increased stability of the hydrates and, consequently, increased resistance to dissociation and (b) higher $Q_{W}$ and $M_{W}$ caused by the increased pressure differential $\Delta P=P_{0}-P_{w}$ (i.e., the driving force of flow to the well).

\subsubsection{Comparison of rates}

The volumetric release and production rates $\left(Q_{R}\right.$ and $Q_{P}$, respectively) per unit thickness of HBS in Figure 8 show remarkably different patterns. As expected, $Q_{R}$ (i) decreases with an increasing $P_{0}$ at a given $t$, and (ii) declines with time for a given $P_{0}$ (Figure 8a). Of particular interest is the estimation of negative $Q_{R}$ values for the higher end of the $P_{0}$ range $\left(P_{0}>=10 \mathrm{MPa}\right)$. This indicates net hydrate formation, as $\mathrm{CH}_{4}$ released from dissociation or emerging from solution in the aqueous phase forms "new" secondary hydrate as it moves from its point of evolution to the well.

The $Q_{P}$ pattern (Figure 8b) is drastically different. At low $P_{0}(<=5.7 \mathrm{MPa}), Q_{P}$ declines (i) with an increasing $P_{0}$ for a given $t$, and (ii) with advancing time for a given $P_{0}$ because of declining gas releases due to increasing hydrate stability. At intermediate $P_{0}$ levels (8Mpa and $10 \mathrm{MPa}$ ), $Q_{P}$ (i) declines with advancing time for a given $P_{0}$, (ii) declines with an increasing $P_{0}$ at early times, while (iii) increasing with an increasing $P_{0}$ at later times $t$ because of increasing contribution to $Q_{P}$ of gas evolving from solution in the aqueous phase as the pressure decreases. 
Finally, the pattern is completely reversed at the upper end of the $P_{0}$ range $\left(P_{0}>=30\right.$ $\mathrm{MPa}$ ). While there is a small contribution of gas from hydrate dissociation to production for $P_{0}=20 \mathrm{MPa}$ for $t<0.2$ days, the majority of the produced gas past that time originates from $\mathrm{CH}_{4}$ dissolved in the aqueous phase, which reaches a maximum at about $t$ $=10$ days before beginning to decline because of formation of "new" hydrate and depletion of dissolved $\mathrm{CH}_{4}$ available for evolution (as the radius of the depressurization zone and the pressure distribution approach a quasi-steady state). For $P_{0}=30 \mathrm{MPa}$, the hydrate is more stable, there is consistently formation of new hydrate, and the entirety of $Q_{P}$ originates from $\mathrm{CH}_{4}$ evolving from solution. Because of the larger $P_{0}$, the $Q_{P}$ maximum is observed at $\mathrm{t}=70$ days (later, and at higher levels, than for $P_{0}=20 \mathrm{MPa}$ for the reasons discussed earlier). The hydrate is at its most stable when $P_{0}=50 \mathrm{MPa}$, resulting in the latest (of all $P_{0}$ cases) appearance of gas at the well at $\mathrm{t}>0.4$ days, with $Q_{P}$ continuously increasing in the 0.4 days $<t<10$ year interval, and exceeding the $\max \left\{Q_{P}\right\}$ long-term levels of all other $P_{0}$ cases . Thus, unlike in any other sensitivity analysis, $Q_{P}>Q_{R}$ for $P_{0}>=20 \mathrm{MPa}$ because the source of gas is $\mathrm{CH}_{4}$ dissolved in the aqueous phase rather than dissociating hydrate.

\subsubsection{Comparison of volumes}

The cumulative volumes of released and produced gas ( $V_{R}$ and $V_{P}$, respectively) per unit thickness of HBS in Figure 9 are consistent with the $Q_{R}$ and $Q_{P}$ patterns discussed in Section 3.4.1 (Figure 8). Thus, $V_{R}$ decreases with an increasing $P_{0}$ at a given $t$ (Figure 9a). The net formation of new hydrate for the higher end of the $P_{0}$ range $\left(P_{0}>=10 \mathrm{MPa}\right)$ is indicated by negative $V_{R}$ values. Conversely, $V_{P}$ increases with an increasing $P_{0}$ at a 
given $t$ (Figure $9 \mathrm{~b}$ ) because the contribution of solution gas to production increases with $P_{0}$, and becomes the exclusive source of gas for $P_{0}>=10 \mathrm{MPa}$. For the same reason (and unlike in any other sensitivity analysis) $V_{P}>V_{R}$ for $P_{0}>=8 \mathrm{MPa}$. However, even at its highest $Q_{R}\left(=4.7 \times 10^{3} \mathrm{ST} \mathrm{m}^{3}\right)$ level for $P_{0}=50 \mathrm{MPa}$, gas production remains very limited and orders of magnitude below generally acceptable levels of economic viability (thus, not meeting the absolute criterion).

\subsubsection{Water production}

The dependence of $Q_{W}$ and $M_{W}$ on $P_{0}$ in Figure 10 further undermines the notion of exploiting Class 4 marine hydrate accumulations as a potential gas source. As expected, (i) $Q_{W}$ and $M_{W}$ increase with $P_{0}$ because of larger pressure differentials $\Delta P$ (leading to linearly increasing water fluxes), and (ii) for a given $P_{0}, Q_{W}$ declines with time. Considering only the best possible case (in terms of gas production) of $P_{0}=50 \mathrm{MPa}, Q_{W}$ increases by a factor of over 15 (and $M_{W}$ by a factor exceeding 20) over the reference case, when the corresponding $Q_{P}$ increases by less than a factor of 5. Thus, the increase in gas production (already too low) is overcome by an even larger undesirable increase in water production. The estimated gas-to-water ratios are unacceptably low for economically viable gas production. Consequently, all cases in the $P_{0}$-sensitivity study fail both the absolute and the relative criterion for gas production feasibility.

\subsection{Sensitivity to initial temperature $T_{0}$}

We varied the $T_{0}$ range from $2{ }^{\circ} \mathrm{C}$ to $18{ }^{\circ} \mathrm{C}$, while keeping the $P_{0}$ at a level $0.2 \mathrm{MPa}$ higher than the equilibrium pressure $P_{H}$ at that temperature. This range covers the $P_{0}-T_{0}$ 
spectrum of measurements of hydrates in natural marine systems (Okhotsk Sea, Guatemala 3 - see Figure 1). The expectation was that a higher $T_{0}$ would lead to higher $Q_{R}, Q_{P}, V_{R}, V_{P}, Q_{W}$ and $M_{W}$ because of (a) lower heat of dissociation, (b) the increasing (with $T_{0}$ ) thermal reservoir to support the endothermic hydrate dissociation reaction, and (c) larger pressures $P_{0}$ (corresponding to the higher $T_{0}$ ) and, consequently, larger depressurization differentials $\Delta P$, larger radii of the dissociation zone, and increased contributions of dissolved gas to production.

The simulation results indicate a strong dependence of $Q_{R}, Q_{P}$ and $V_{R}, V_{P}$ on $T_{0}$. The rates and cumulative production volumes increase by orders of magnitude (Figures 11 and 12) in response to increases of a few degrees in $T_{0}$ (Figures 11 and 12) because of the aforementioned reasons. However, even at the highest temperature $T=18{ }^{\circ} \mathrm{C}, Q_{P}$ and $V_{P}$ $\left(=1.4 \times 10^{4} \mathrm{ST} \mathrm{m}^{3}\right.$ after 10 years of production) are still orders of magnitude below levels generally acceptable as economically viable. The increase in $T_{0}$ leads to considerably larger water production (as quantified by $Q_{W}$ and $M_{W}$ in Figure 13) through the correspondingly larger $P_{0}$, which in turn leads to linearly larger aqueous phase fluxes because of a higher differential $\Delta P$ between the well and the HBS.

A final general observation is that variations in the initial $T_{0}$ (and the corresponding $P_{0}$ ) do not lead to any production figures that meet either the absolute and the relative criterion for economically successful gas production from disperse, low- $S_{H}$ hydrate accumulations. 


\subsection{Sensitivity to initial saturation $S_{H}$}

We varied the $S_{H}$ range between 0.02 and 0.1 , while keeping all other variables and parameters as in the reference case. This range is representative of hydrates in natural marine systems [11] (see discussion in Section 2.4). The expectation was that higher $S_{H}$ would lead to (a) higher $Q_{R}, Q_{P}, V_{R}$, and $V_{P}$ because of increased hydrate availability, and (b) to lower $Q_{W}$ and $M_{W}$ because of more adverse relative permeability conditions of the aqueous phase.

Review of $Q_{R}$ (Figure 14a) and $V_{R}$ (Figure 15a) shows a very weak dependence on $S_{H}$. The effect of $S_{H}$ on $Q_{R}$ and $V_{R}$ is consistent with expectations, (i.e., increasing with $S_{H}$ ) only at very early times $(\mathrm{t}<10$ days), and hydrate dissociation appears practically insensitive to $S_{H}$ in longer-term production scenarios. The larger initial $Q_{R}$ and $V_{R}$ for $S_{H}$ $=0.10$ is attributed to the availability of more hydrate at the higher $S_{H}$, in addition to the stronger pressure drop effected by the corresponding lower effective permeability. However, this effect appears to weaken rapidly, and the practical insensitivity of $Q_{R}$ and $V_{R}$ to $S_{H}$ indicates that the increased hydrate availability and lower effective $k$ at higher $S_{H}$ are balanced by the larger dissociation radius in the more permeable HBS with lower $S_{H}$.

Conversely, $Q_{P}$ and $V_{P}$ show a markedly more pronounced response to variations in $S_{H}$ (Figures $14 \mathrm{~b}$ and $15 \mathrm{~b}$ ), increasing consistently with an increasing $S_{H}$. Their behavior is consistent with expectations, and is caused by the effect of the irreducible gas saturation $S_{i r G}$. HBS with lower $S_{H}$ yield lower gas volumes, of which a larger portion is immobilized in the porous media before flow to the well becomes possible when $S_{G}>$ 
$S_{i r G}$, thus resulting in the relationships depicted by Figures $14 \mathrm{~b}$ and $15 \mathrm{~b}$. The $Q_{W}$ and $M_{W}$, in Figures 16a and 16b, respectively, are consistent with the expected system behavior, and show water production increasing with a decreasing $S_{H}$ because of greater availability of water and enhanced relative permeability to water. However, the effect is relatively minor because of the low $S_{H}$ typical of the Class 4 deposits considered in this study.

As in all previous cases, review of Figures 14 to 16 leads to the inevitable observation that variations in initial $S_{H}$ that span the range of expected values in Class 4 deposits yield production predictions that fail both the absolute and the relative criterion for economically successful gas production from disperse, low- $S_{H}$ hydrate accumulations.

\subsection{Sensitivity to well pressure $P_{w}$}

We considered three $P_{w}$ levels: $2.7 \mathrm{MPa}$ (slightly above the quadruple point of methane hydrate - the reference case), 1.5 $\mathrm{MPa}$, and 0.5 MPa. In this set of simulations, we kept all other variables and parameters as in the reference case. The expectation was that lower $P_{w}$ would result in higher $Q_{R}, Q_{P}, V_{R}, V_{P}, Q_{W}$ and $M_{W}$ because of larger depressurization differentials $\Delta P$ (i.e., the driving force of flow), larger radii of the dissociation zone, and increased contributions of dissolved gas to production.

The evolution of $Q_{R}, Q_{P}, V_{R}, V_{P}, Q_{W}$ and $M_{W}$ (Figures 17 to 19) with time is consistent with expectations, with all these parameters increasing consistently (but sub-linearly) with $P_{w}$. However, even at $P_{w}$ as low as $0.5 \mathrm{MPa}$, the $Q_{P}$ and $V_{P}$ (Figures $17 \mathrm{~b}$ and $18 \mathrm{~b}$ ) remain orders of magnitude below levels that could be considered potentially appealing 
for commercial gas production, while increases in water production (Figure 19) easily overwhelm the limited gains in gas production. As in all previous cases, variations in $P_{w}$ fail to lead predictions even approaching economic feasibility of gas production from disperse, low- $S_{H}$ hydrate accumulations. It is important to note that, although production in two of the cases investigated here involved $P_{w}$ below the $\mathrm{CH}_{4}$-hydrate quadruple point, ice was not observed in the system because the low $S_{H}$ was insufficient to effect a substantial temperature drop during the endothermic process of dissociation.

\section{Summary and Conclusions}

The current study is part of a wider investigation that aims to determine the most promising hydrate accumulations as early production targets, on which initial effort and resources (including scientific analysis, engineering research, exploration, and field testing) are to be focused. In this study we investigated depressurization-induced gas production from a variety of disperse, low- $S_{H}$ (Class 4 ) hydrate accumulations in oceanic sediments.

Using numerical simulation, we estimated (a) the rates of gas production $Q_{P}$ and gas release $Q_{R}$ from hydrate dissociation, (b) the corresponding cumulative volumes of released and produced gas ( $V_{P}$ and $V_{R}$, respectively), as well as (c) the water production rate $Q_{W}$ and the mass of produced water $M_{W}$ over a 10 -year production period. Because we investigated gas production under a constant-pressure regime at the well, $Q_{R}, Q_{P}, V_{R}$, $V_{P}, Q_{W}$ and $M_{W}$ were expected to decline with time. We investigated the sensitivity of items (a) to (c) to the following hydraulic properties, reservoir conditions, and operational 
parameters: intrinsic permeability $k$, porosity $\phi$, initial pressure $P_{0}$, initial temperature $T_{0}$, hydrate saturation $S_{H}$, and constant pressure $P_{w}$ at which the production well is kept. We evaluated the production potential of Class 4 hydrate deposits using two criteria: an absolute criterion of sufficiently high gas production, and a relative criterion of an acceptably high gas-to-water ratio.

The results of this study indicated that $Q_{R}, Q_{P}, V_{R}, V_{P}, Q_{W}$ and $M_{W}$ increase with $k, T_{0}$, and $P_{w}$, and that these relationships were relatively strong. Conversely, although $Q_{R}, Q_{P}$, $V_{R}, V_{P}, Q_{W}$ and $M_{W}$ increase with $\phi$, the dependence is very weak. Although $Q_{R}$ and $V_{R}$ appeared insensitive to $S_{H}$ variations (in the $S_{H}$ range that is typical of marine Class 4 HBS), the corresponding $Q_{P}, V_{P}, Q_{W}$ and $M_{W}$ increased with $S_{H}$, albeit slowly.

Finally, $Q_{R}$ and $V_{R}$ increase with a decreasing $P_{0}$ because of the reduced hydrate stability that the lower pressure entails, and negative $Q_{R}$ and $V_{R}$ are possible at very high $P_{0}$ levels (i.e., indicating very stable hydrates) because of secondary hydrate formation. The corresponding $Q_{R}$ and $V_{R}$ exhibited the opposite relationship to $P_{0}$ because of the increasing contribution of gas evolving from solution (as opposed to released from dissociation) as the initial pressure increased.

Despite covering the entire spectrum of expected variations in system properties, initial conditions, and operational parameters of such systems, the results indicate consistently very low gas production volumes that are further encumbered with very large water production, and we have been unable to identify conditions leading to economically 
viable gas production. The overall conclusion drawn from this study is that such Class 4 deposits are not promising targets for gas production.

\section{Acknowledgment}

The LBNL portion of this work (G. Moridis) was supported by the Assistant Secretary for Fossil Energy, Office of Natural Gas and Petroleum Technology, through the National Energy Technology Laboratory, under the U.S. Department of Energy, Contract No. DEAC03-76SF00098. E.D. Sloan is grateful for support to the CSM Hydrate Consortium: (BP, Chevron, ConocoPhillips, ExxonMobil, Halliburton, and Shell). The authors are indebted to Matthew Reagan, John Apps and Dan Hawkes for their thorough review and their insightful comments.

\subsection{References}

[1] Hammerschmidt EG. Formation of gas hydrates in natural gas transmission lines. Ind Eng Chem 1934: 26: 851-60.

[2] Max MD, Johnson AH, Dillon WP, editors. Economic geology of natural gas hydrates. Amsterdam: Springer-Verlag; 2006.

[3] Kennett JP, Cannariato KG, Hendy IL, Behl, RJ, Methane hydrates in Quaternary climate change: The hydrate gun hypothesis. Washington, DC: American Geophysical Union; 2003.

[4] Ginsburg, GD, Soloviev, VA. Submarine gas hydrates. St. Petersburg;1998.

[5] Paull CK, Dillon WP, editors. Natural gas hydrates: Occurrence, distribution and detection. Washington, DC: American Geophysical Union; 2001.

[6] Sanden K, Rushfeldt P, Graff OF, Gudmundsson JS, Masuyama N, Nishii T. Long distance transport of natural gas hydrate to Japan. In: Austvik T, editor. Proceedings of Fifth International Conference on Gas Hydrates, 1355, June 13-16, 2005, Trondheim Norway. 
[7] Moridis GJ, Collett TS. Strategies for gas production from hydrate accumulations under various geologic conditions. Report LBNL-52568, Lawrence Berkeley National Laboratory, Berkeley, CA; 2003.

[8] Moridis GJ, Kowalsky MB, and Pruess K. Depressurization-induced gas production from Class 1 hydrate deposits. SPE 97266, 2005 SPE Annual Technical Conference and Exhibition, Dallas, Texas, U.S.A., 9 - 12 October 2005.

[9] Kvenvolden K. Personal communication November 28; 2005.

[10] Milkov AV. Global estimates of hydrate-bound gas in marine sediments: how much is really out there? Earth-Science Reviews 2004: 66: 183-89.

[11] Klauda JB, Sandler, SI. Global distribution of methane hydrate in ocean sediment. Energy \& Fuels 2005: 19: 469-78.

[12] Radler, M. World crude and natural gas reserves rebound in 2000. Oil and Gas Journal 2000: 98: 121-30.

[13] Makogon YF. Hydrates of natural gas. Moscow: Nedra, Izadatelstro;1974 (in Russian - Translated and published by PennWell Books, Tulsa, Oklahoma; 1981).

[14] Sloan, E.D., Clathrate Hydrates of Natural Gases, (2 ${ }^{\text {nd }}$ Edition) pp 513ff., Marcel Dekker, Inc., New York, (1988).

[15] Booth JS, Rowe MM, Fischer KM. Offshore gas hydrate sample database. USGS Open-File Report 96-272, June 1996.

[16] Gupta AR. Personal communication in CSM Hydrate Group, January 3, 2006.

[17] Holder GD., Kamath VA, Godbole SP. The potential of gas hydrates as an energy resource. Ann Rev Energy 1984: 9:427-38.

[18] Moridis GJ, Kowalsky MB, Pruess K. TOUGH-Fx/HYDRATE v1.0 User's Manual: A code for the simulation of system behavior in hydrate-bearing geologic media. Report LBNL-58950. Lawrence Berkeley National Laboratory, Berkeley, CA; 2005.

[19] Kim HC, Bishnoi PR, Heidemann RA, Rizvi SSH. Kinetics of methane hydrate decomposition. Chem Eng Sci 1987: 42(7):1645-58.

[20] Clarke MA, Bishnoi PR. Determination of the activation energy and intrinsic rate constant of methane gas hydrate decomposition, Can J Chem Eng 2001: 79(1): 143147. 
[21] Makogon YF. Natural gas hydrates: The state of study in the USSR and perspectives for its use. Presented at $3{ }^{\text {rd }}$ Chemical Congress of North America, Toronto, Canada, June 5-10; 1988.

[22] Dallimore SR, Collett TS. Scientific results from the Mallik 2002 gas hydrate production research well program, Mackenzie Delta, Northwest Territories, Canada. Dallimore SR, Collett TS, editors, Geological Survey of Canada Bulletin 585, Ottawa; 2005.

[23] Paull CK, Matsumoto R, Wallace PJ, et al. Sites 994, 995, and 996. Proceedings of the Ocean Drilling Project Initial Reports 164 1996: 164: 99.

[24] Trehu AM, Bohrmann G, Rack F, et al. Three-dimensional distribution of gas hydrate beneath southern hydrate ridge: Constraints from ODP Leg 204. Earth and Planetary Science Letters 2004: 222: 845-55.

[25] Moridis GJ, Seol Y, Kneafsey T. Studies of reaction kinetics of methane hydrate dissociation in porous media. In: Austvik T, editor. Proceedings of Fifth International Conference on Gas Hydrates, paper 1004, 21-30, June 13-16; 2005 (also Report LBNL-57298, Lawrence Berkeley National Laboratory, Berkeley, CA; 2005.

[26] van Genuchten MT. A closed-form equation for predicting the hydraulic conductivity of unsaturated soils. Soil Sci Soc 1980: 44: 892-900.

[27] Stone HL. Probability model for estimating three-phase relative permeability. Trans SPE of AIME 1970: 249: 214-220. 


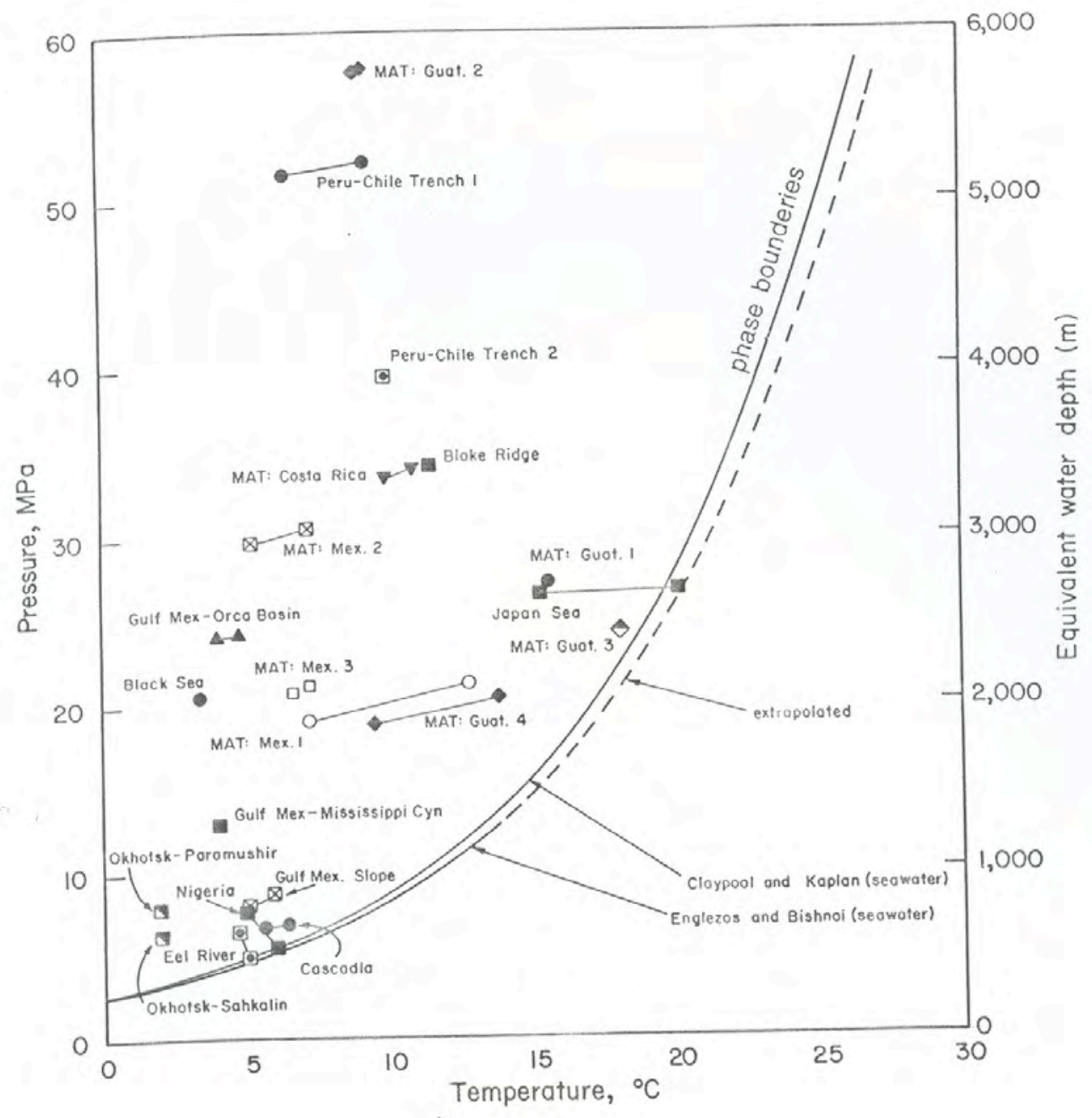

Figure 1. Compilation of Data for Recovered Hydrate Samples in Relation to the Three Phase Boundary (courtesy of Booth et al. [15]) 


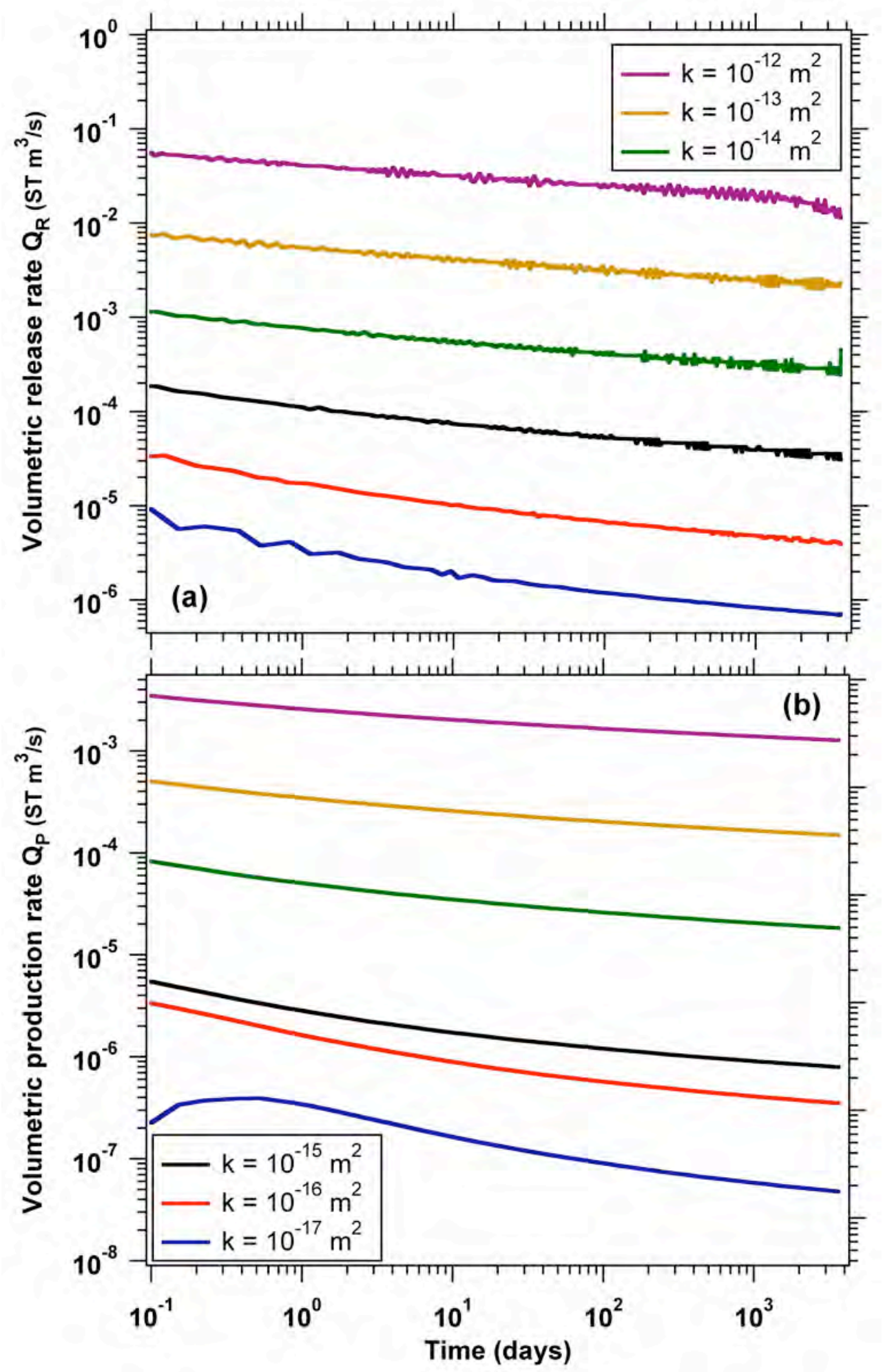

Figure 2. Sensitivity of (a) the volumetric rate of gas release from hydrate dissociation $Q_{R}$, and (b) the volumetric rate of gas production at the well $Q_{P}$ to variations in the intrinsic permeability $k$. Note: $Q_{R}$ and $Q_{P}$ correspond to a unit HBS thickness. 

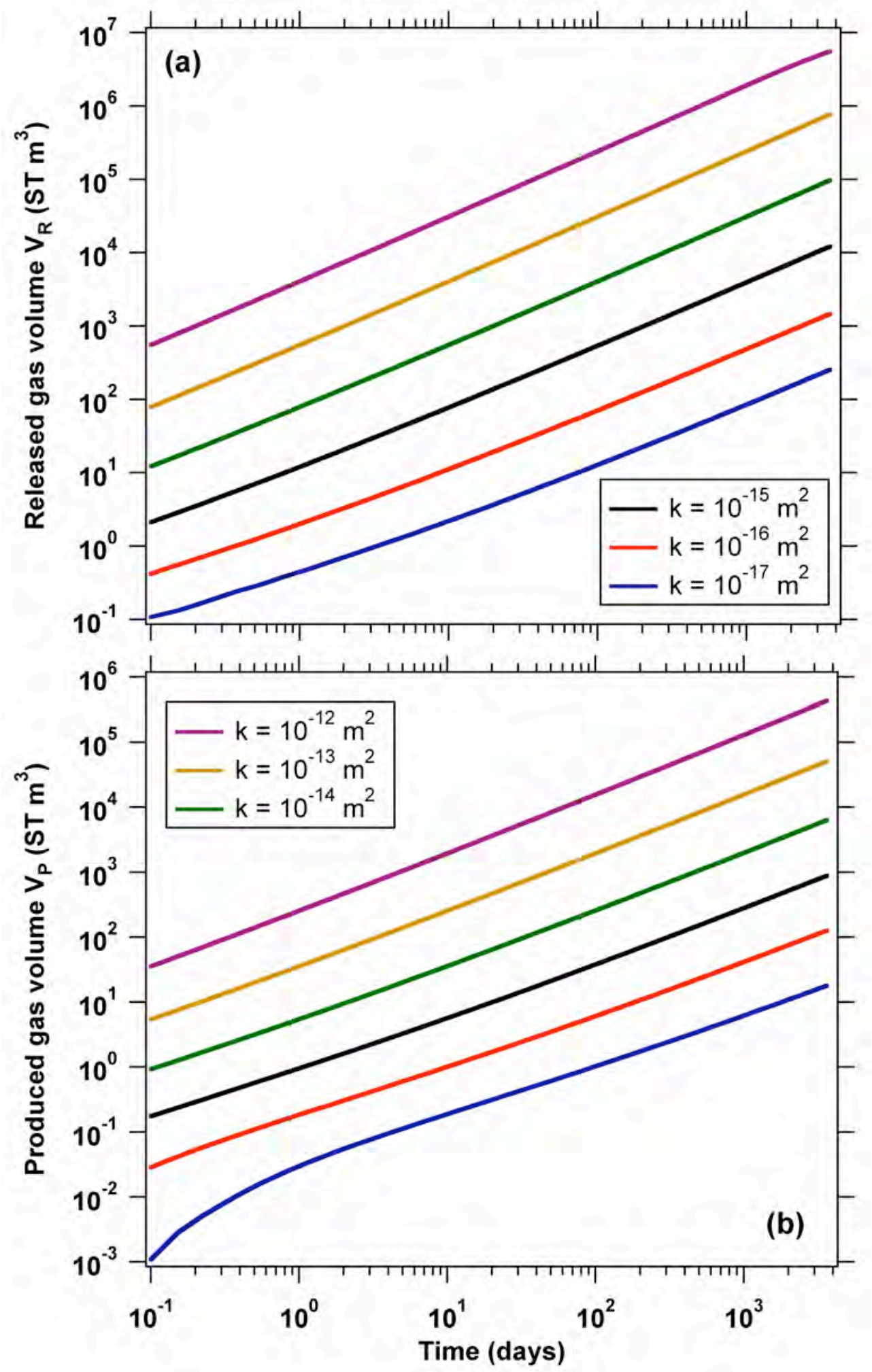

Figure 3. Sensitivity of (a) the cumulative volume of gas released from hydrate dissociation $V_{R}$, and (b) the cumulative volume of gas produced at the well $V_{P}$ to variations in the intrinsic permeability $k$. Note: $V_{R}$ and $V_{P}$ correspond to a unit HBS thickness. 


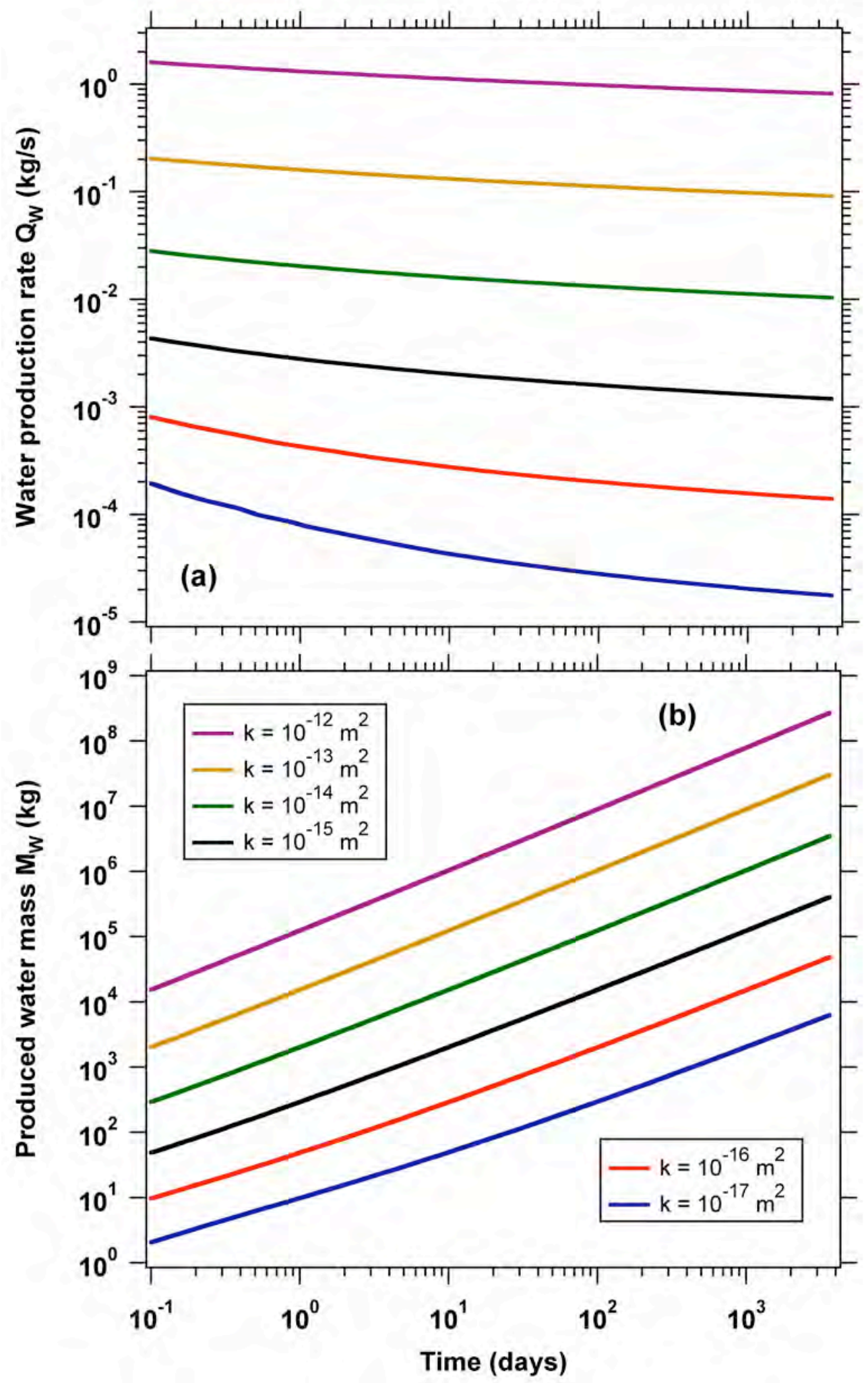

Figure 4. Sensitivity of (a) the mass rate of water production $Q_{W}$, and (b) the cumulative mass of water produced at the well $M_{W}$ to variations in the intrinsic permeability $k$. Note: $Q_{W}$ and $M_{W}$ correspond to a unit HBS thickness. 


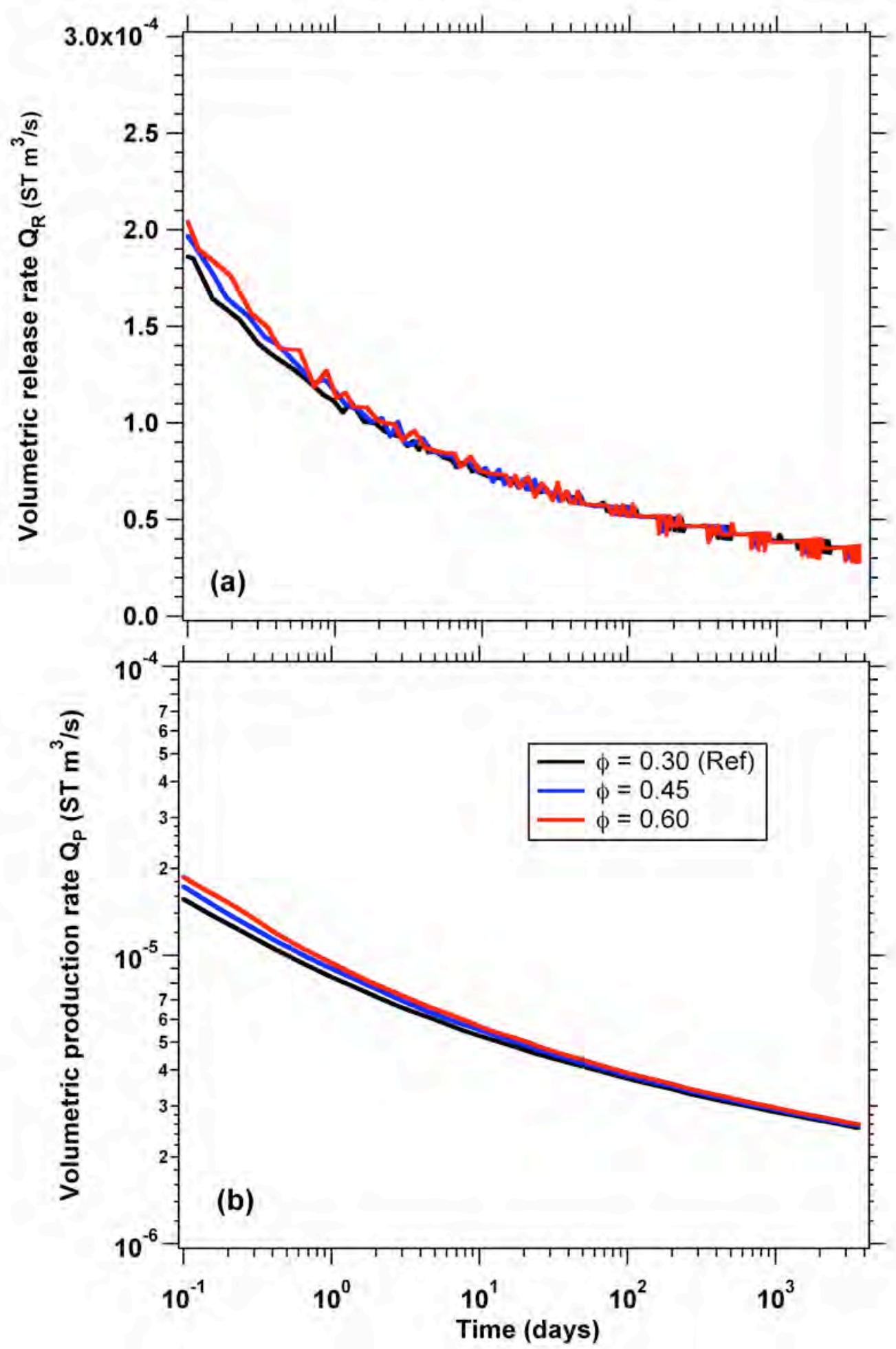

Figure 5. Sensitivity of (a) the volumetric rate of gas release from hydrate dissociation $Q_{R}$, and (b) the volumetric rate of gas production at the well $Q_{P}$ to variations in the porosity $\phi$. Note: $Q_{R}$ and $Q_{P}$ correspond to a unit HBS thickness. 


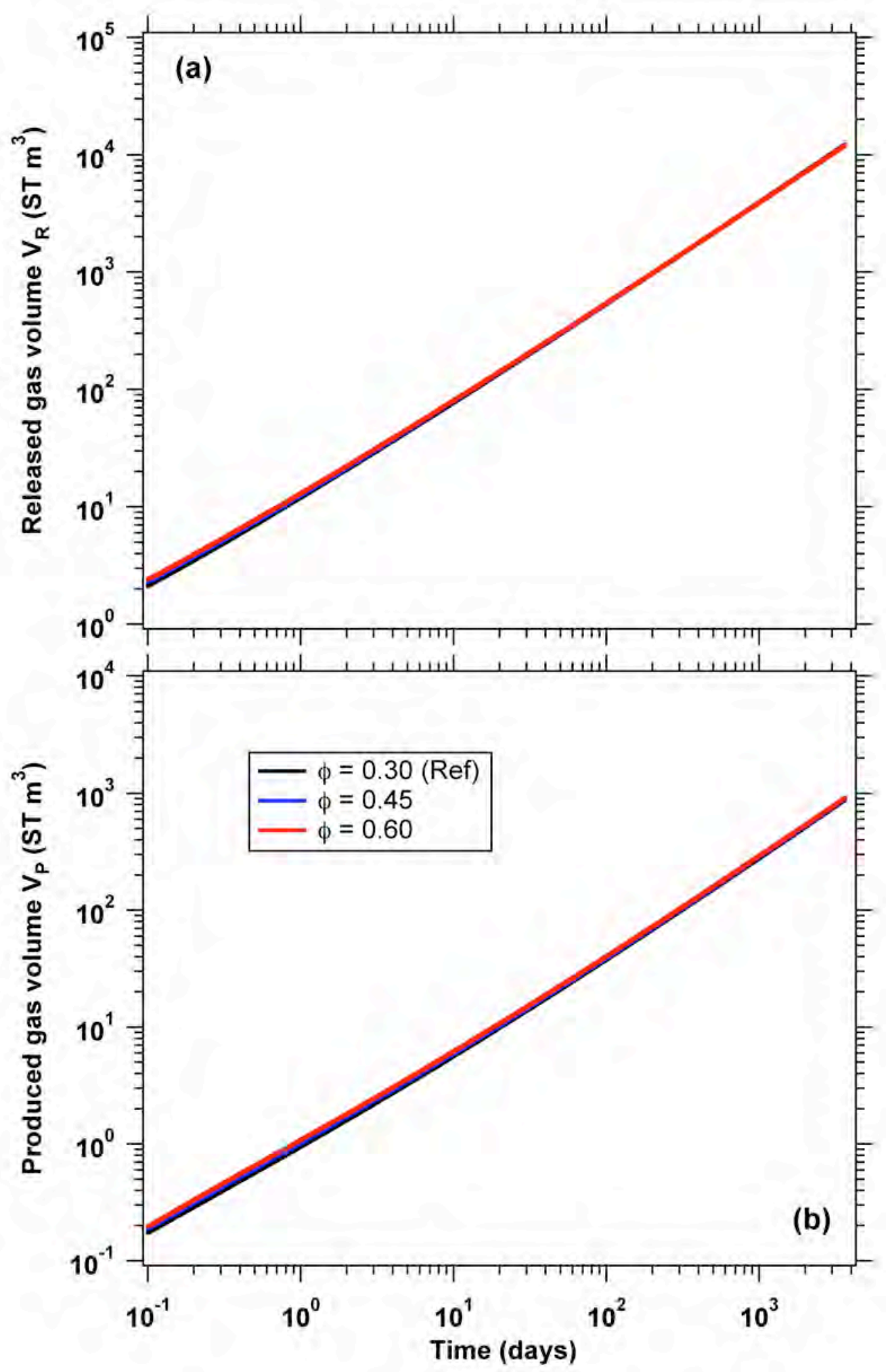

Figure 6. Sensitivity of (a) the cumulative volume of gas released from hydrate dissociation $V_{R}$, and (b) the cumulative volume of gas produced at the well $V_{P}$ to variations in the porosity $\phi$. Note: $V_{R}$ and $V_{P}$ correspond to a unit HBS thickness. 

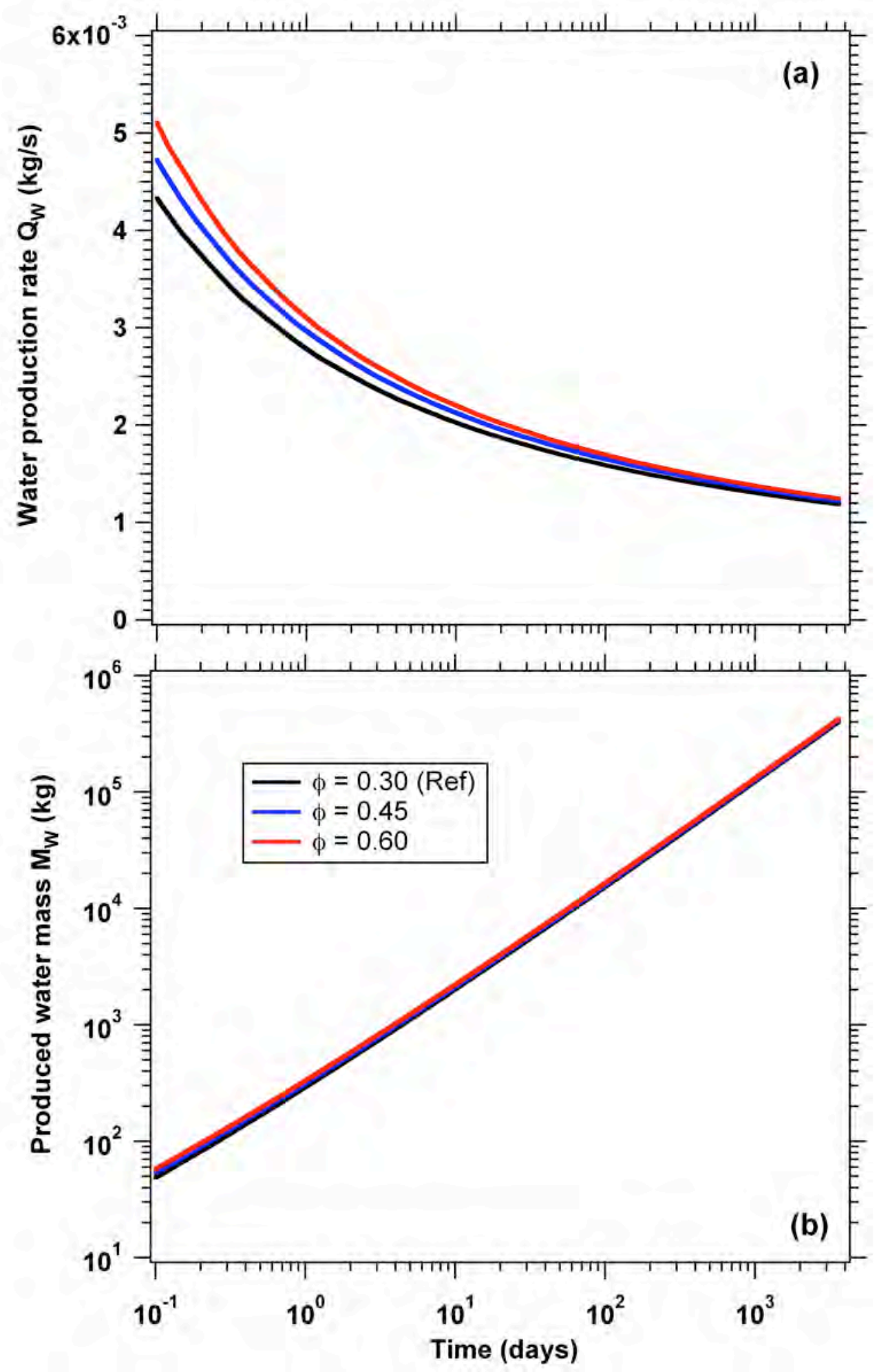

Figure 7. Sensitivity of (a) the mass rate of water production $Q_{W}$, and (b) the cumulative mass of water produced at the well $M_{W}$ to variations in the porosity $\phi$. Note: $Q_{W}$ and $M_{W}$ correspond to a unit HBS thickness. 

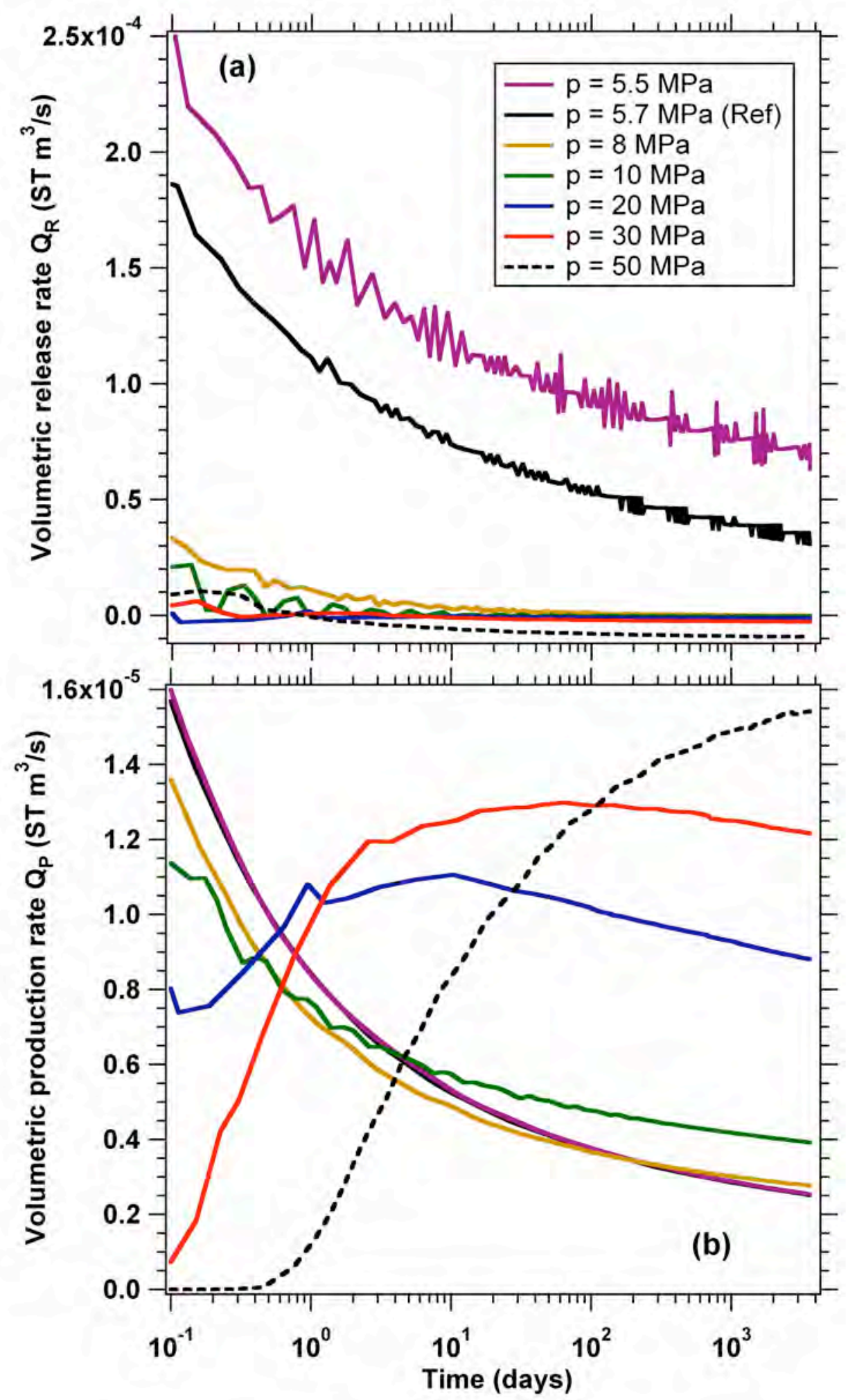

Figure 8. Sensitivity of (a) the volumetric rate of gas release from hydrate dissociation $Q_{R}$, and (b) the volumetric rate of gas production at the well $Q_{P}$ to variations in the initial pressure $P_{0}$ when $T_{0}=6{ }^{\circ} \mathrm{C}$. Note: $Q_{R}$ and $Q_{P}$ correspond to a unit HBS thickness. 

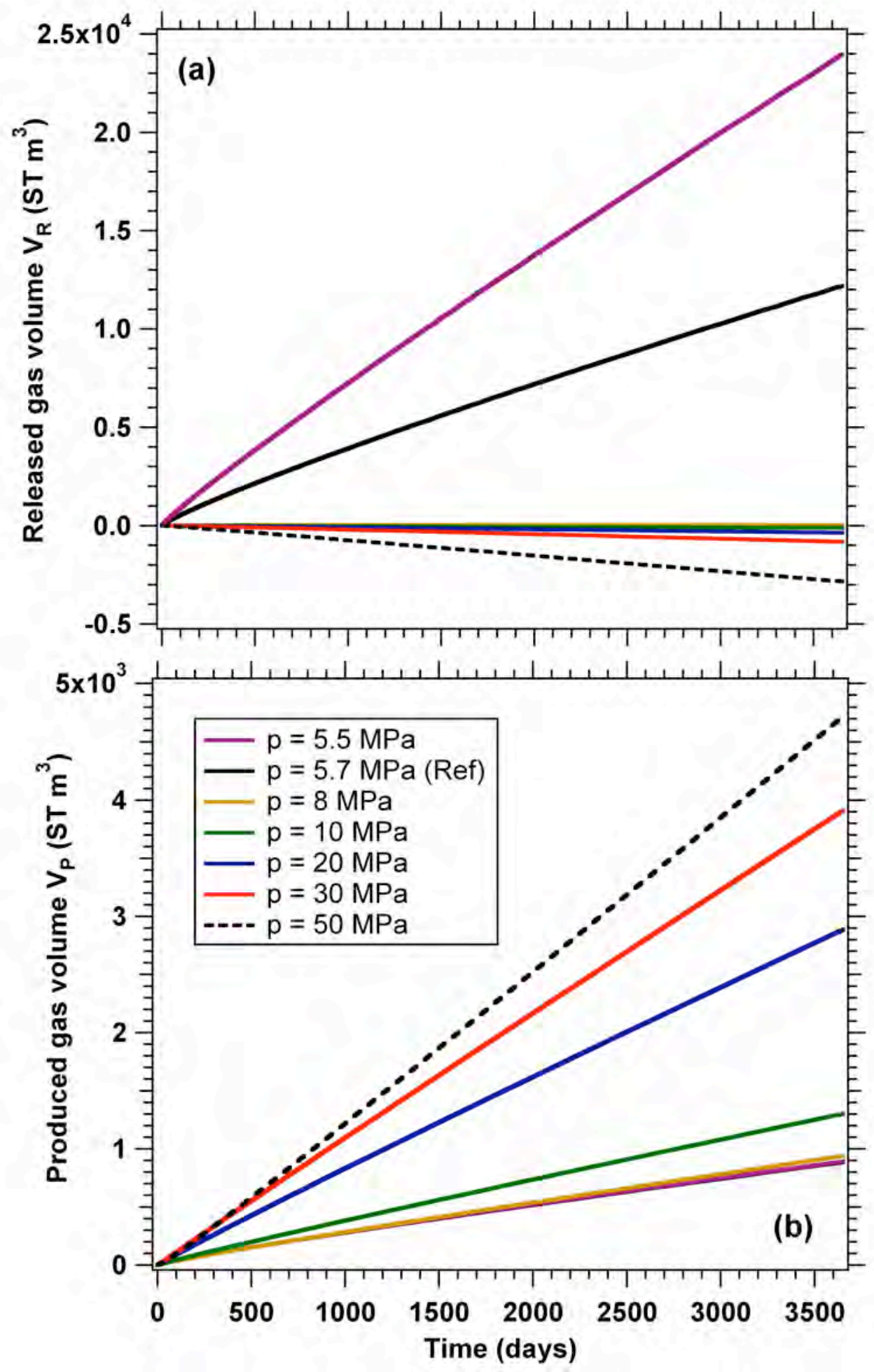

Figure 9. Sensitivity of (a) the cumulative volume of gas released from hydrate dissociation $V_{R}$, and (b) the cumulative volume of gas produced at the well $V_{P}$ to variations in the initial pressure $P_{0}$ when $T_{0}=6{ }^{\circ} \mathrm{C}$. Note: $V_{R}$ and $V_{P}$ correspond to a unit HBS thickness. 

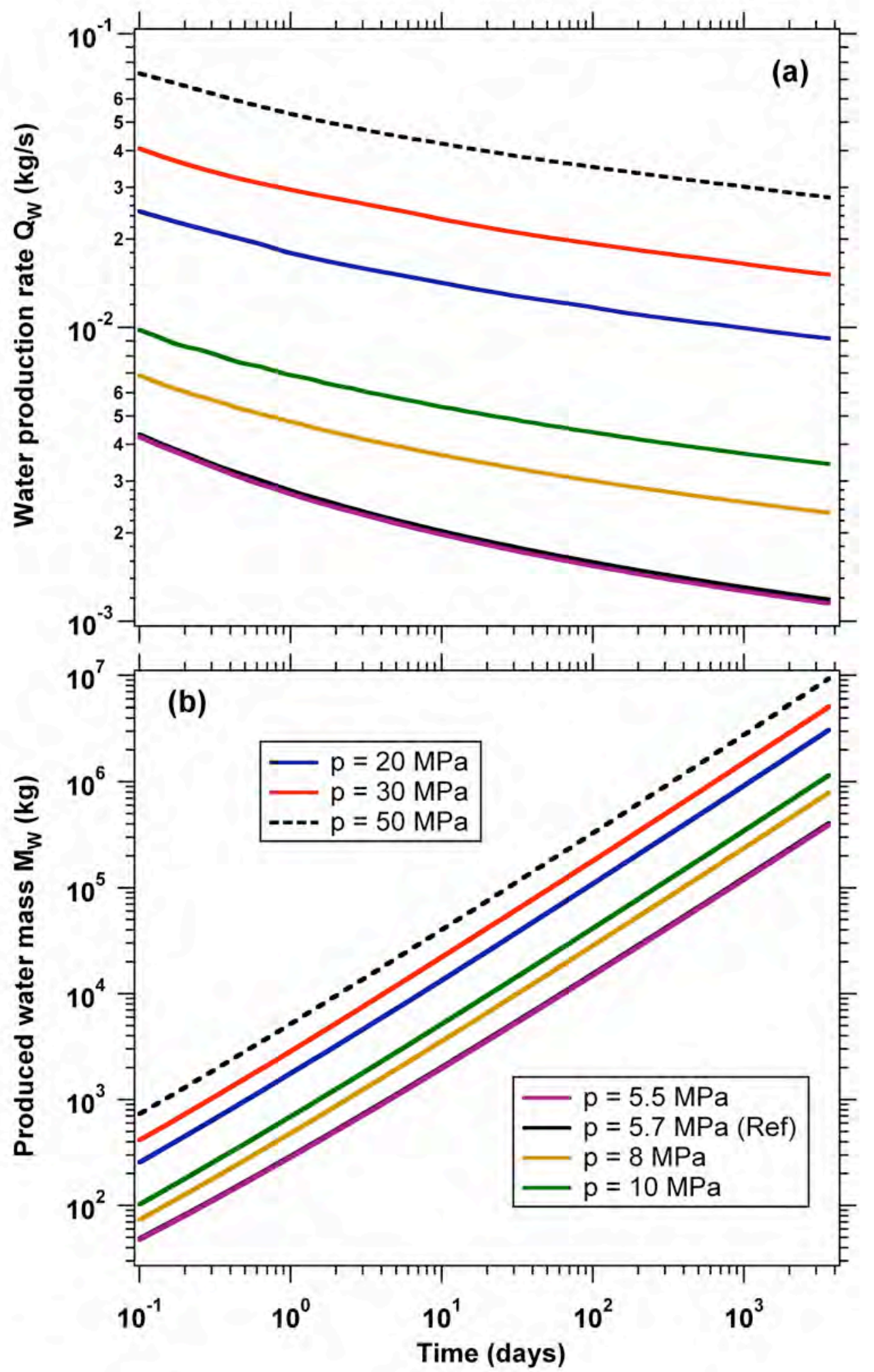

Figure 10. Sensitivity of (a) the mass rate of water production $Q_{w}$, and (b) the cumulative mass of water produced at the well $M_{W}$ to variations in the initial pressure $P_{0}$ when $T_{0}=6{ }^{\circ} \mathrm{C}$. Note: $Q_{W}$ and $M_{W}$ correspond to a unit HBS thickness. 


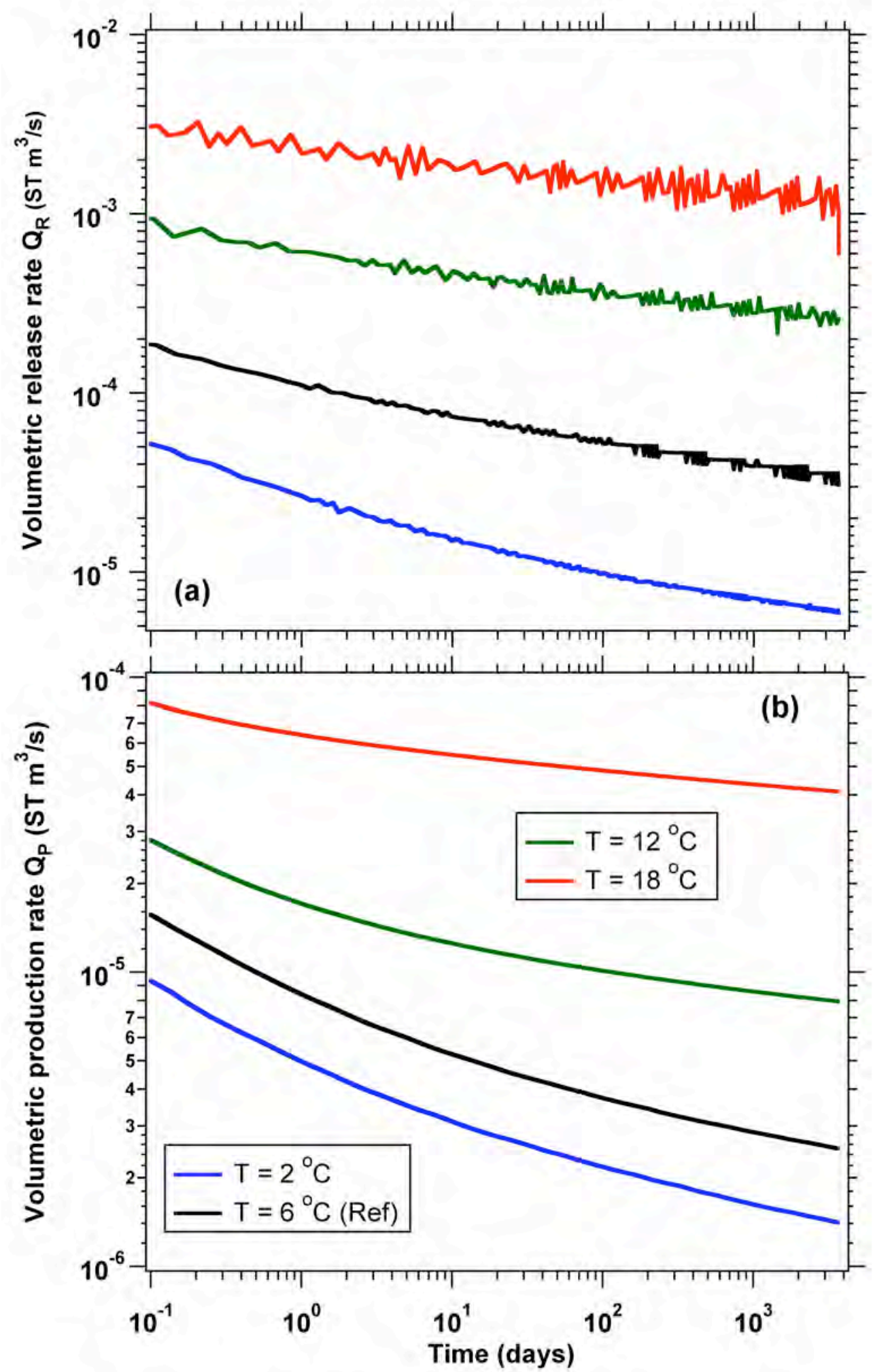

Figure 11. Sensitivity of (a) the volumetric rate of gas release from hydrate dissociation $Q_{R}$, and (b) the volumetric rate of gas production at the well $Q_{P}$ to variations in the initial temperature $T_{0}$. Note: $Q_{R}$ and $Q_{P}$ correspond to a unit HBS thickness. 


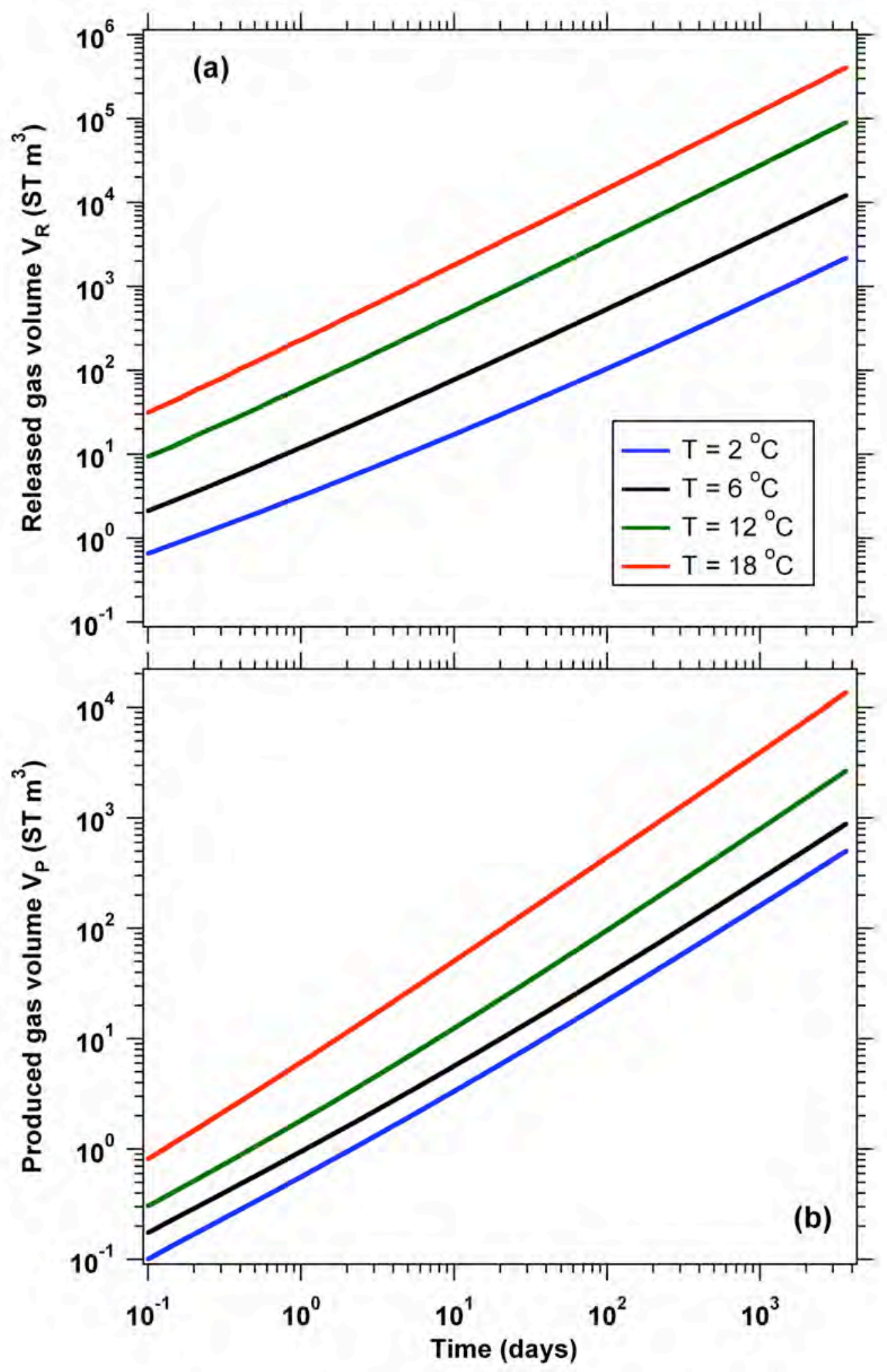

Figure 12. Sensitivity of (a) the cumulative volume of gas released from hydrate dissociation $V_{R}$, and (b) the cumulative volume of gas produced at the well $V_{P}$ to variations in the initial temperature $T_{0}$. Note: $V_{R}$ and $V_{P}$ correspond to a unit HBS thickness. 

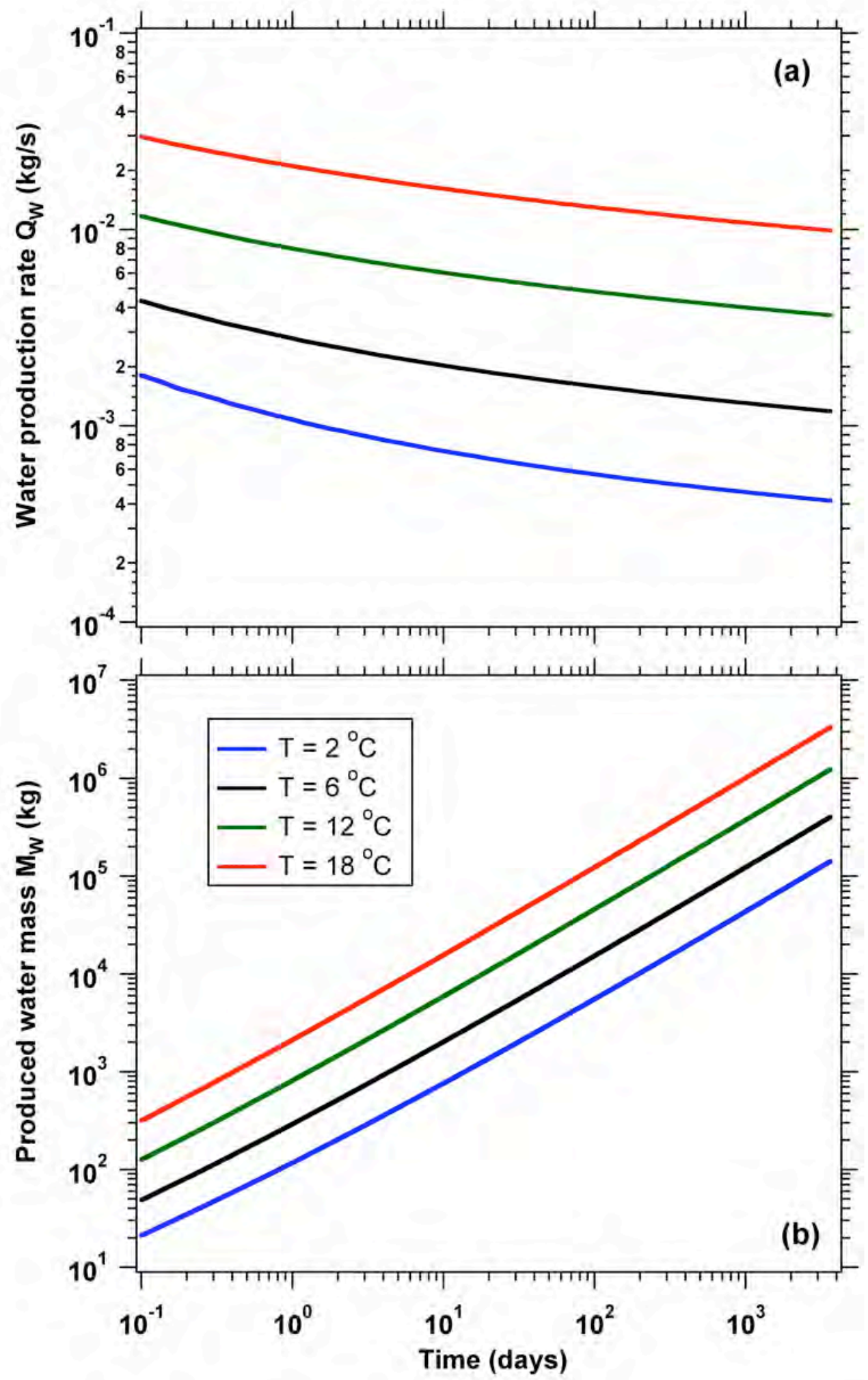

Figure 13. Sensitivity of (a) the mass rate of water production $Q_{w}$, and (b) the cumulative mass of water produced at the well $M_{W}$ to variations in the initial temperature $T_{0}$. Note: $Q_{W}$ and $M_{W}$ correspond to a unit HBS thickness. 


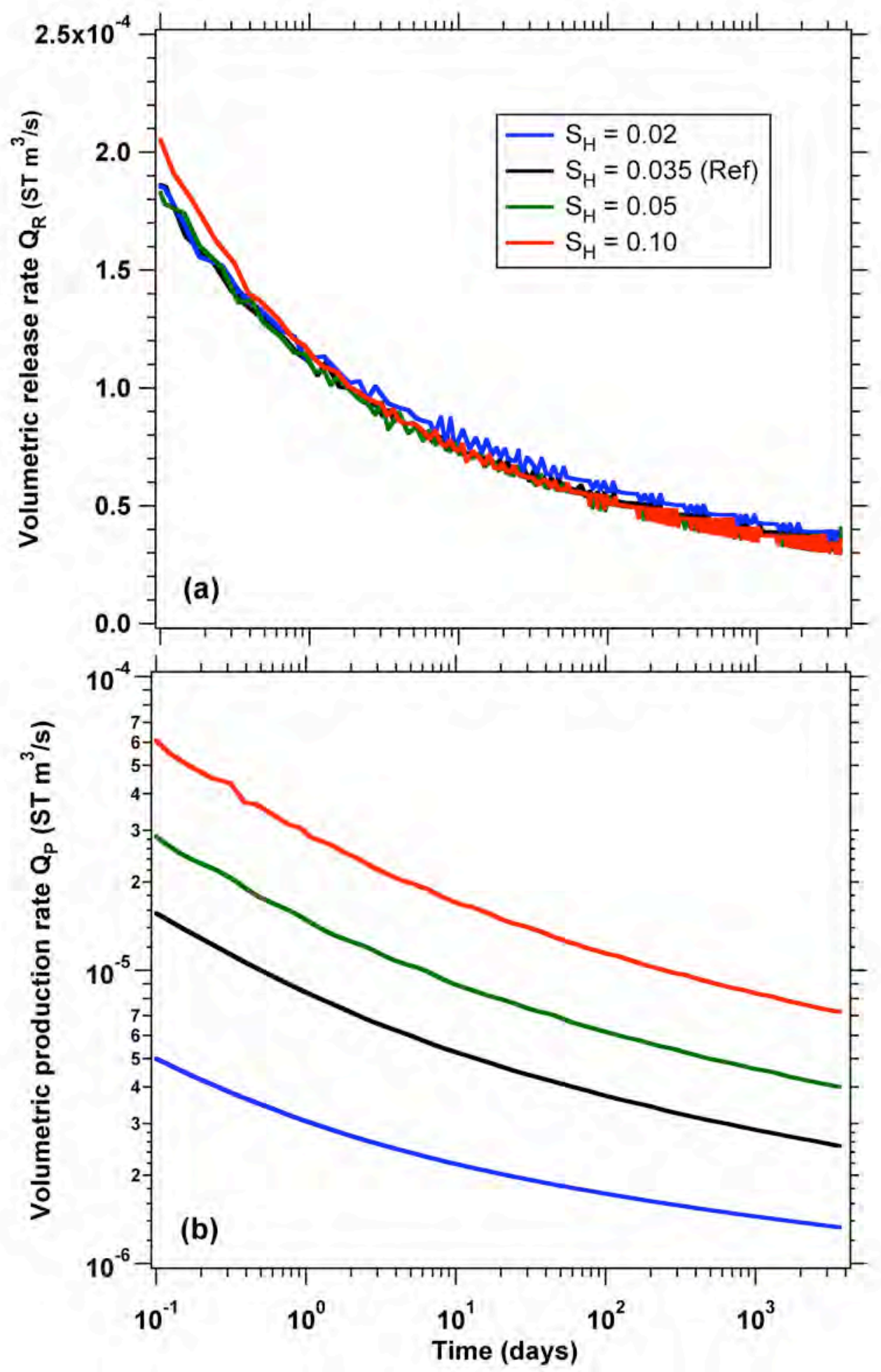

Figure 14. Sensitivity of (a) the volumetric rate of gas release from hydrate dissociation $Q_{R}$, and (b) the volumetric rate of gas production at the well $Q_{P}$ to variations in the initial hydrate saturation $S_{H}$. Note: $Q_{R}$ and $Q_{P}$ correspond to a unit HBS thickness. 

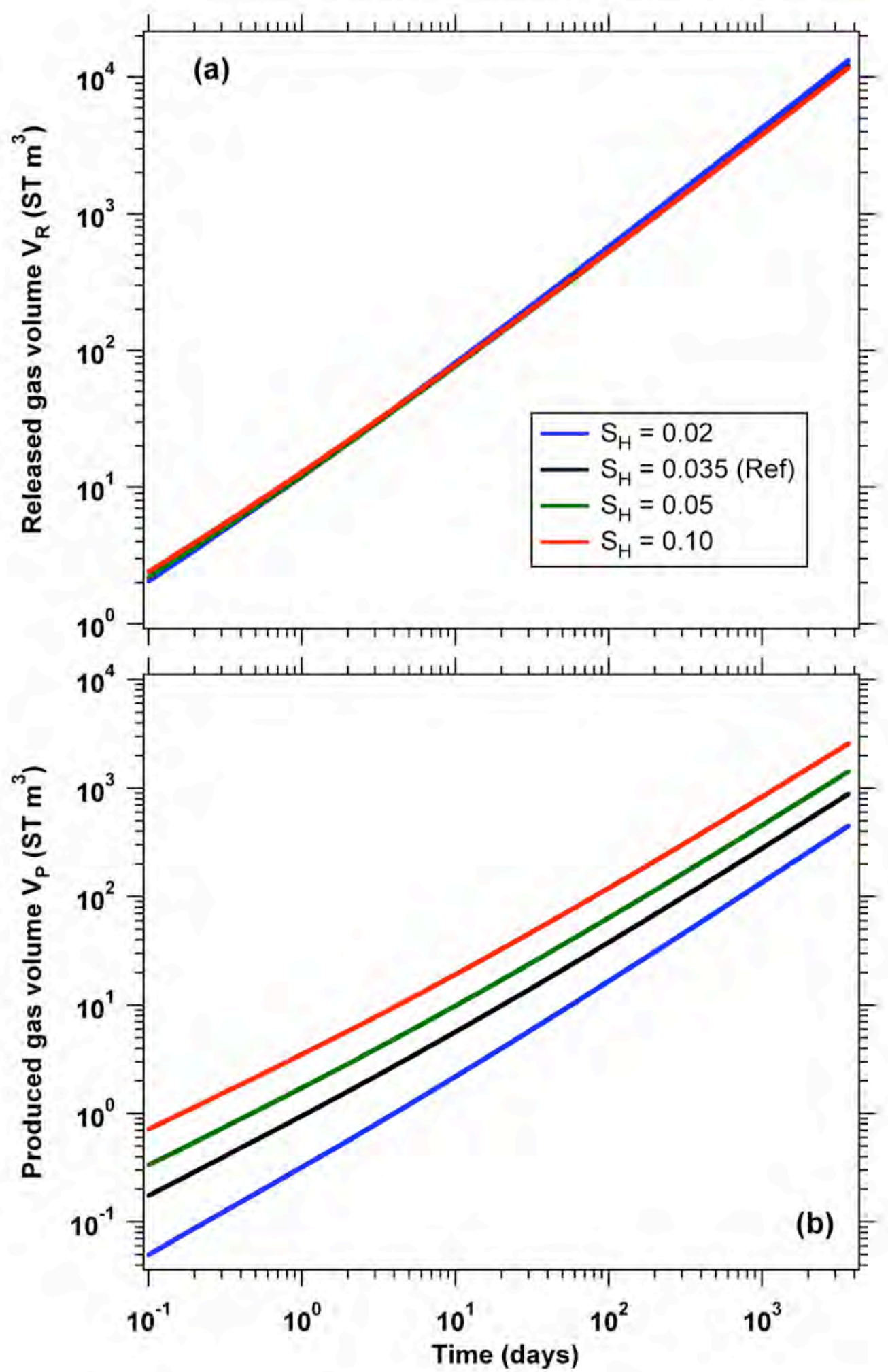

Figure 15. Sensitivity of (a) the cumulative volume of gas released from hydrate dissociation $V_{R}$, and (b) the cumulative volume of gas produced at the well $V_{P}$ to variations in the initial hydrate saturation $S_{H}$. Note: $V_{R}$ and $V_{P}$ correspond to a unit HBS thickness. 

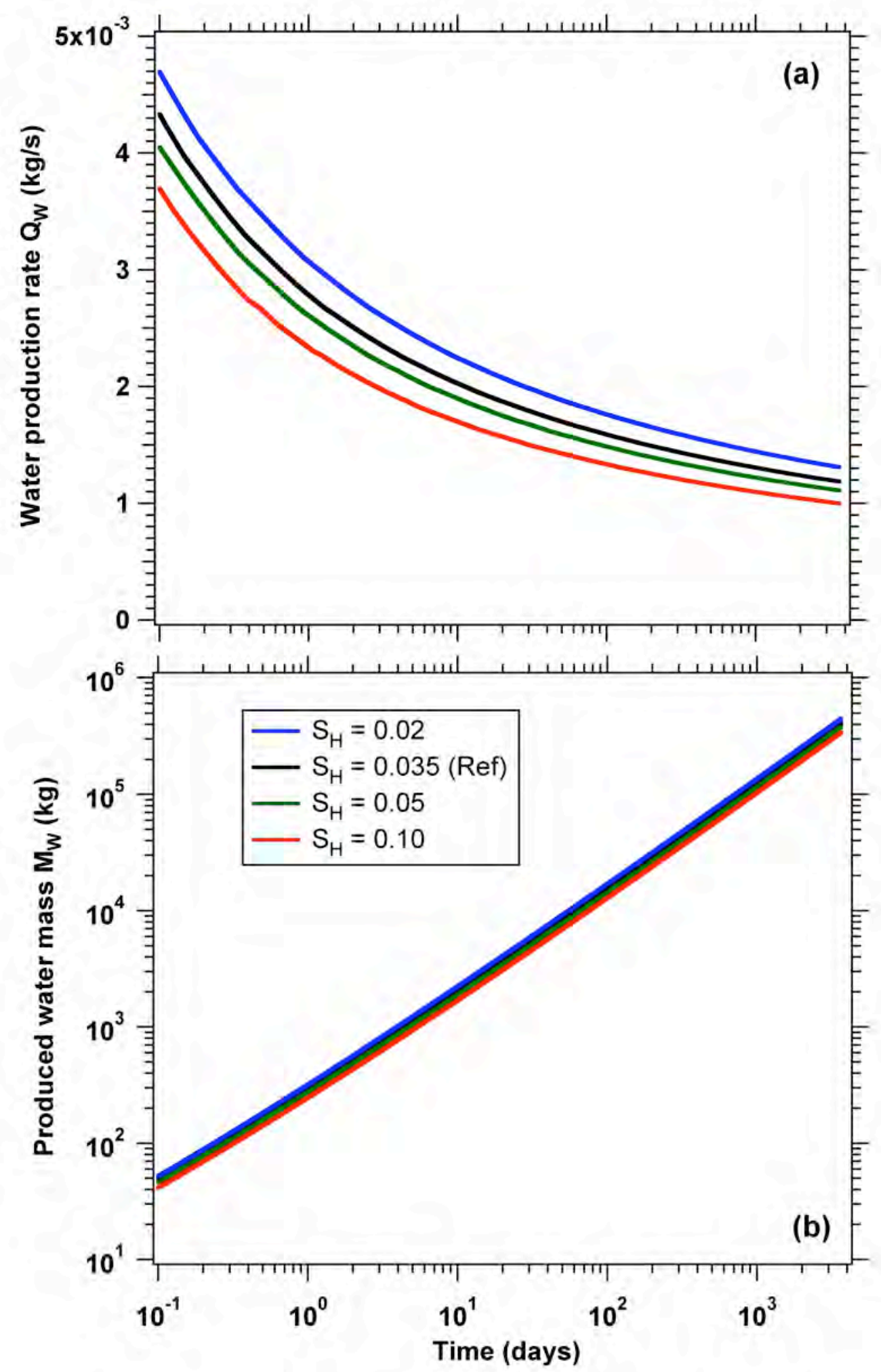

Figure 16. Sensitivity of (a) the mass rate of water production $Q_{W}$, and (b) the cumulative mass of water produced at the well $M_{W}$ to variations in the initial hydrate saturation $S_{H}$. Note: $Q_{W}$ and $M_{W}$ correspond to a unit HBS thickness. 


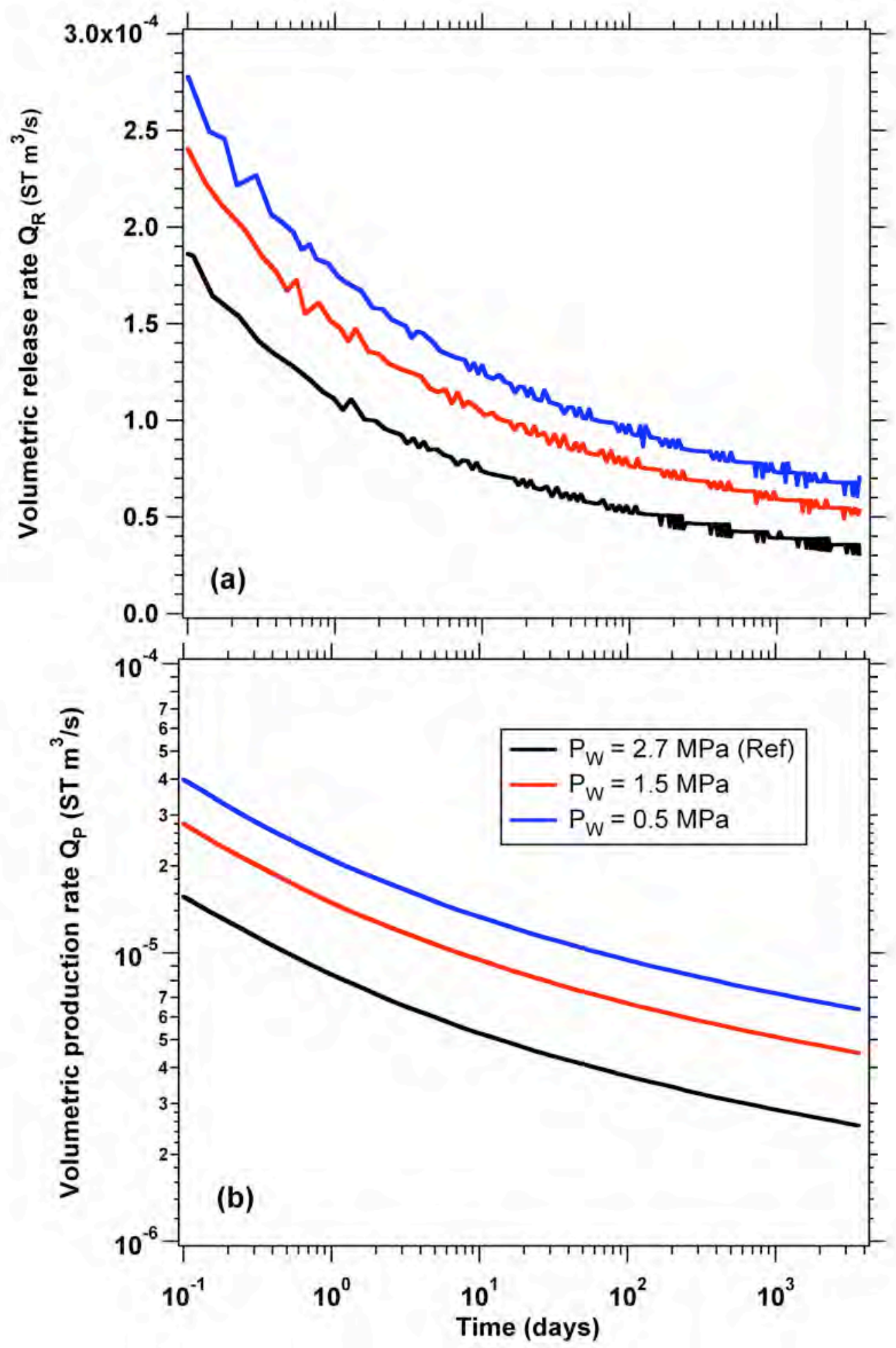

Figure 17. Sensitivity of (a) the volumetric rate of gas release from hydrate dissociation $Q_{R}$, and (b) the volumetric rate of gas production at the well $Q_{P}$ to variations in the well pressure $P_{w}$. Note: $Q_{R}$ and $Q_{P}$ correspond to a unit HBS thickness. 


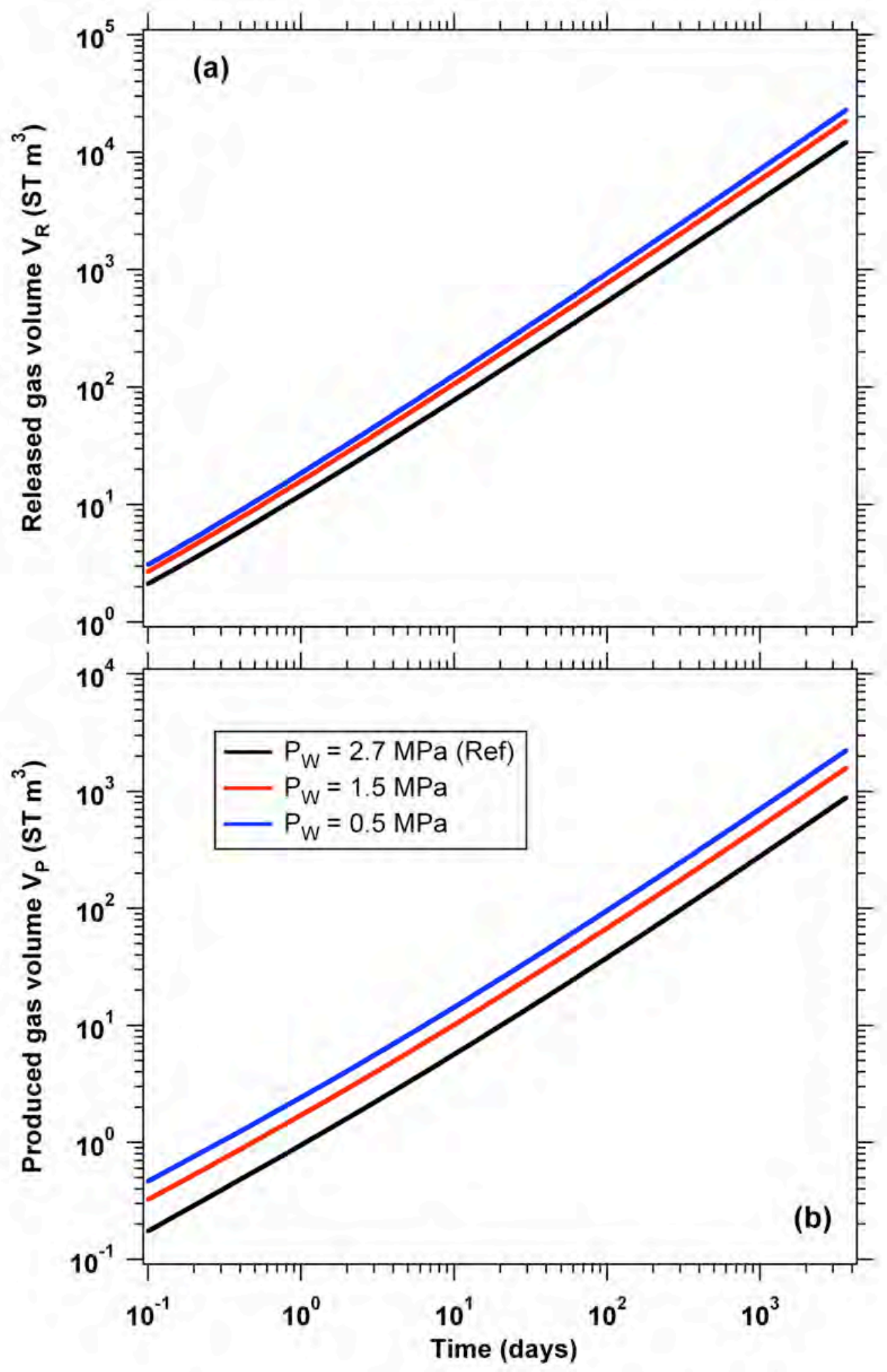

Figure 18. Sensitivity of (a) the cumulative volume of gas released from hydrate dissociation $V_{R}$, and (b) the cumulative volume of gas produced at the well $V_{P}$ to variations in the well pressure $P_{w}$. Note: $V_{R}$ and $V_{P}$ correspond to a unit HBS thickness. 

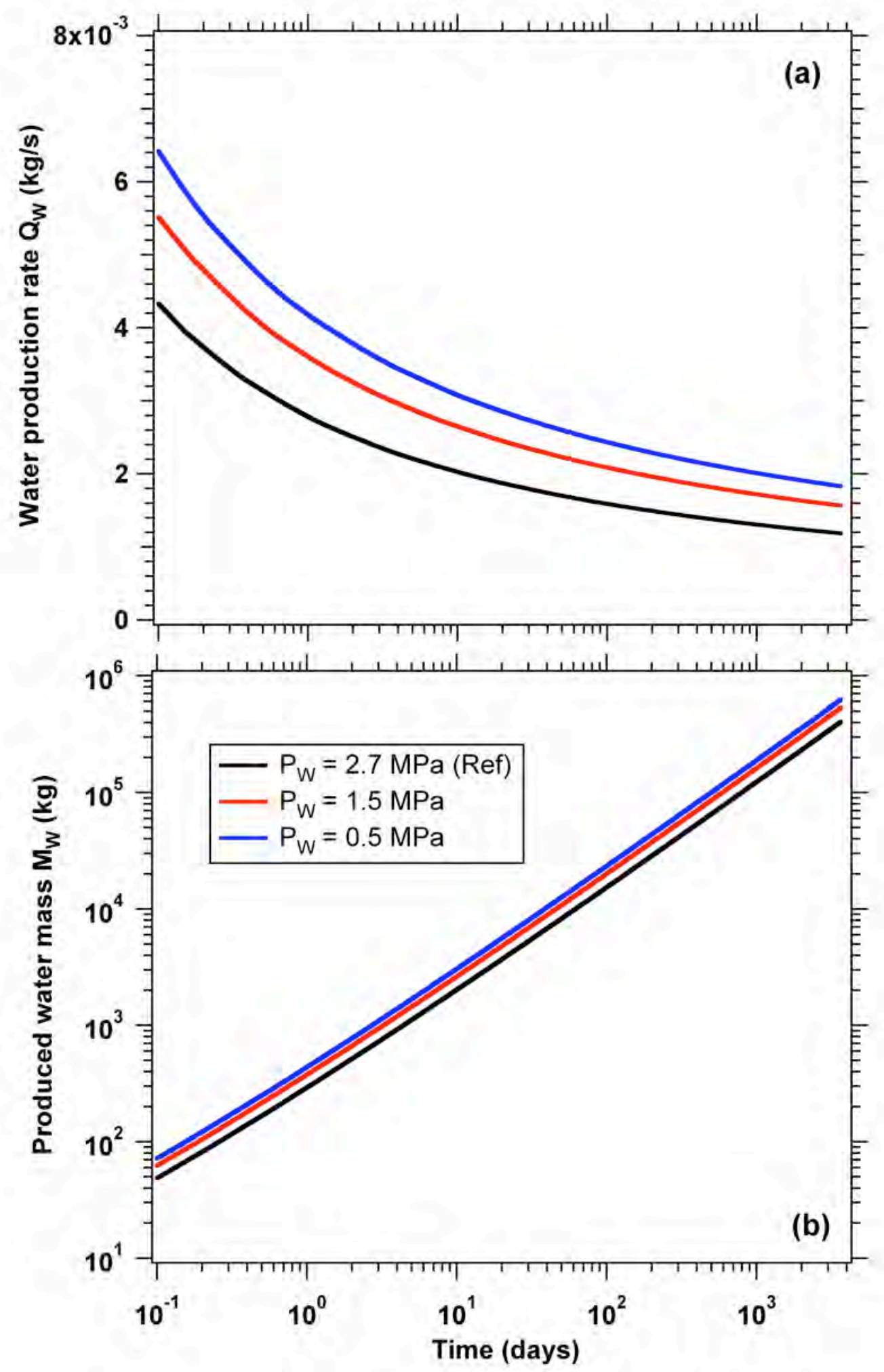

Figure 19. Sensitivity of (a) the mass rate of water production $Q_{w}$, and (b) the cumulative mass of water produced at the well $M_{w}$ to variations in the well pressure $P_{w}$. Note: $Q_{W}$ and $M_{W}$ correspond to a unit HBS thickness. 


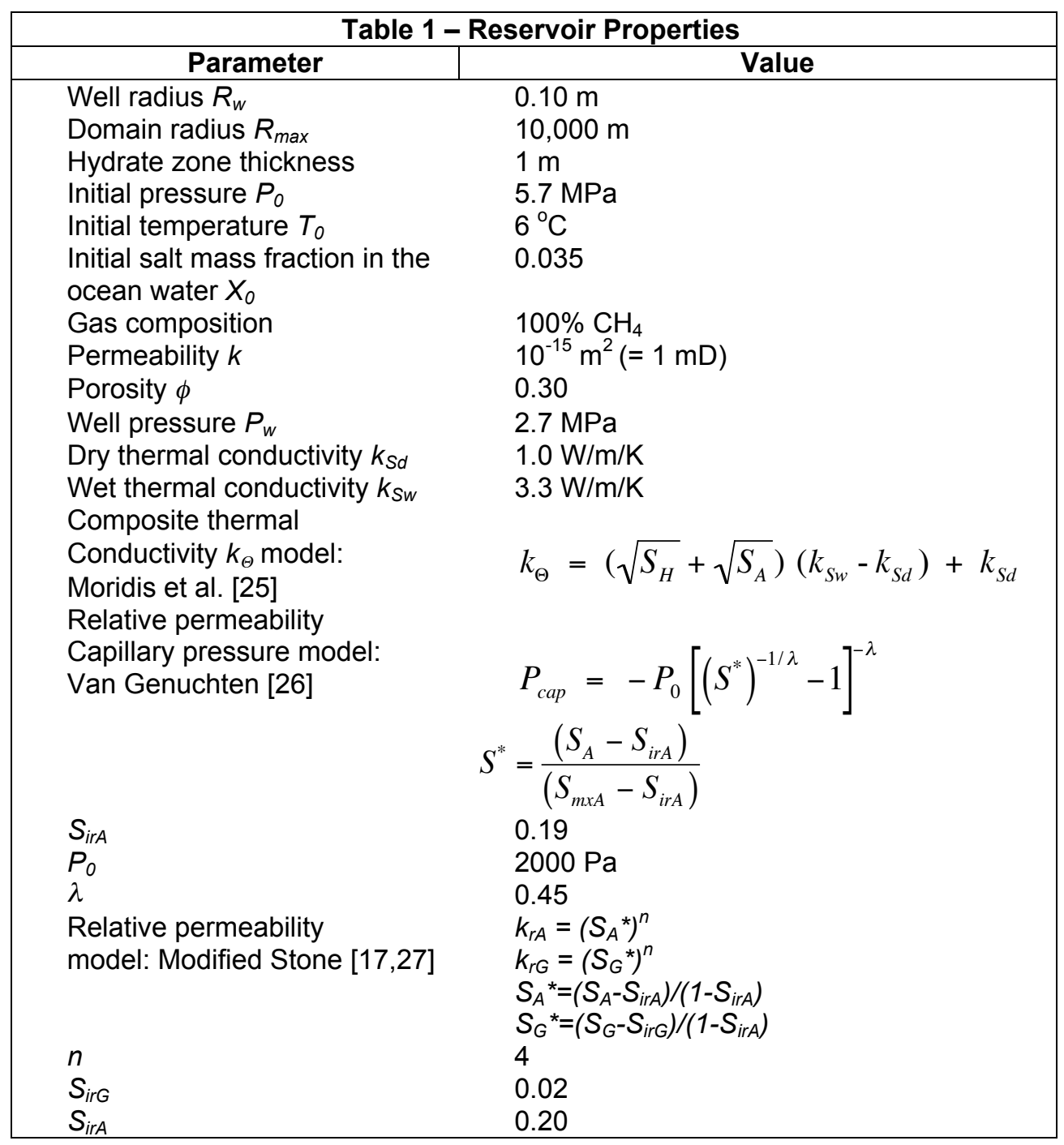

